\title{
The Use of a Vortex Insertion Technique to Simulate the Extratropical Transition of Hurricane Michael (2000)
}

\author{
Christopher T. Fogarty \\ Canadian Hurricane Centre, Dartmouth, Nova Scotia, Canada \\ Richard J. Greatbatch AND Harold Ritchie \\ Department of Oceanography, Dalhousie University, Halifax, Nova Scotia, Canada
}

(Manuscript received 27 May 2005, in final form 30 October 2006)

\begin{abstract}
On 19 October 2000, Hurricane Michael merged with an approaching baroclinic trough over the western North Atlantic Ocean south of Nova Scotia. As the hurricane moved over cooler sea surface temperatures (SSTs; less than $25^{\circ} \mathrm{C}$ ), it intensified to category-2 intensity on the Saffir-Simpson hurricane scale [maximum sustained wind speeds of $44 \mathrm{~m} \mathrm{~s}^{-1}(85 \mathrm{kt})$ ] while tapping energy from the baroclinic environment. The large "hybrid" storm made landfall on the south coast of Newfoundland with maximum sustained winds of $39 \mathrm{~m} \mathrm{~s}^{-1}(75 \mathrm{kt})$ causing moderate damage to coastal communities east of landfall. Hurricane Michael presented significant challenges to weather forecasters. The fundamental issue was determining which of two cyclones (a newly formed baroclinic low south of Nova Scotia or the hurricane) would become the dominant circulation center during the early stages of the extratropical transition (ET) process. Second, it was difficult to predict the intensity of the storm at landfall owing to competing factors: 1) decreasing SSTs conducive to weakening and 2) the approaching negatively tilted upper-level trough, favoring intensification. Numerical hindcast simulations using the limited-area Mesoscale Compressible Community model with synthetic vortex insertion (cyclone bogus) prior to the ET of Hurricane Michael led to a more realistic evolution of wind and pressure compared to running the model without vortex insertion. Specifically, the mesoscale model correctly simulates the hurricane as the dominant circulation center early in the transition process, versus the baroclinic low to its north, which was the favored development in the runs not employing vortex insertion. A suite of experiments is conducted to establish the sensitivity of the ET to various initial conditions, lateral driving fields, domain sizes, and model parameters. The resulting storm tracks and intensities fall within the range of the operational guidance, lending support to the possibility of improving numerical forecasts using synthetic vortex insertion prior to ET in such a model.
\end{abstract}

\section{Introduction \\ a. Background}

Many numerical weather prediction models used to study and predict the movement and intensity of tropical cyclones (TCs) rely on an accurate representation of the storm in the initial conditions. There are various means by which numerical TC models are initialized. Most are initialized with a synthetic hurricane vortex (also known as a "bogus" vortex and referred to as vortex specification), which is an idealized three-

Corresponding author address: Christopher T. Fogarty, Canadian Hurricane Centre, 45 Alderney Dr., 3d Floor, Dartmouth, NS B2Y 2N6, Canada.

E-mail: chris.fogarty@ec.gc.ca dimensional representation of the real storm in gradient wind balance with a symmetric moist core structure, extending through the troposphere. The synthetic vortex is typically constructed prior to running the primary forecast or research model, and is then inserted and blended with the ambient meteorological fields, giving improved initial conditions for the model.

Agencies that utilize a synthetic vortex or synthetic observations to initiate numerical hurricane forecast models include the Met Office (UKMET; Heming and Radford 1998), the Geophysical Fluid Dynamics Laboratory (GFDL; Kurihara et al. 1995), and the Tropical Cyclone-Limited Area Prediction System (TC-LAPS) developed at the Australian Bureau of Meteorology Research Centre (Davidson and Weber 2000), among others. The UKMET global model is initialized with

DOI: 10.1175/WAF1014.1

(C) 2007 American Meteorological Society 
synthetic tangential surface wind observations located at specific points around the storm center, and at specified vertical levels. The synthetic winds are matched as closely as possible to real information on storm intensity, provided by the National Hurricane Center (NHC). A second example is the GFDL model, which has a more sophisticated vortex initialization scheme whereby an axisymmetric version of the primary (GFDL) model is used to build an idealized vortex, run for $60 \mathrm{~h}$ from an initially motionless state. During the vortex generation phase, the wind field of the developing vortex is "nudged" toward a target wind field that is consistent with the real storm. The fully developed vortex is then inserted and blended with the ambient environment, providing the initial atmospheric state for the main model run. The ambient environment and lateral boundary conditions for the limited-area GFDL model are provided by the Global Forecast System (GFS). As a third example, the TC-LAPS prediction system merges synthetic observations from the storm region, with large-scale (real) observations to produce coarse- and high-resolution objective analyses from a four-dimensional data assimilation procedure. The synthetic observations are taken from a three-dimensional synthetic idealized vortex constructed using information on observed storm size, storm motion, and intensity (Davidson et al. 1993). A 24-h diabatic, dynamical nudging integration using satellite imagery is run with output from the high-resolution objective analysis as the initial condition. The output from this integration produces the initial conditions for the main highresolution forecast, which is driven at the lateral boundaries by a comparatively coarse limited-area forecast model.

Vortex specification is a suitable approach for initializing numerical hurricane models when the TC is well developed (i.e., at least hurricane strength) in the tropical or subtropical latitudes, and is not experiencing dramatic structural changes owing to environmental influences, such as vertical wind shear. The procedures described above can generally be applied until the storm moves out of the subtropics, moves over land, weakens over cold water, or undergoes extratropical transition (ET). In physical terms, the vortex insertion procedure involves the introduction of additional heat and moisture over a deep layer of the troposphere, and additional kinetic energy (in terms of the wind and pressure field) at the observed location of the storm that are significantly lacking in the original analysis fields.

Relatively little is known about the effects and appropriateness of employing vortex specification on numerical simulations of ET. Jones et al. (2003) caution that continued implementation of a synthetic vortex (as a TC migrates into the middle latitudes) may delay the onset of ET in the numerical model. Evans et al. (2006) analyzed the impact of vortex specification on the evolution of ET in the context of cyclone phase space analyses developed by Hart (2003). They found that employing vortex insertion improves the numerical forecasts during the early stages of ET, but can degrade the forecast later in the integration. Given this behavior, employing vortex insertion prior to ET may only have utility over short forecast periods [on the order of 24-36 $\mathrm{h}$ according to Evans et al. (2006)]. In a study of eight transitioning TCs in the Atlantic basin, Hart and Evans (2004) found that storms initialized with a synthetic vortex prior to transition were likely to retain an exaggerated warm core structure after ET was complete, when compared with a model that employed vortex relocation. ${ }^{1}$ On the other hand, an initially weakly represented TC may undergo ET too soon.

Different approaches for initializing the TC in numerical case studies of ET have been applied. For example, McTaggart-Cowan et al. (2001) conducted numerical simulations of the ET of Hurricane Earl in 1998. Their simulations were initialized directly from objective analyses ( $\sim 35 \mathrm{~km}$ horizontal resolution) after the storm had weakened from its tropical phase, but before a period of significant reintensification. A synthetic vortex was not necessary in this case since the low pressure area was adequately represented in the analysis. In a numerical study of the heavy rainfall during the ET of Hurricane Floyd in 1999, Colle (2003) initialized simulations using 0-h Eta Model fields ( $\sim 32 \mathrm{~km}$ horizontal resolution). The intensity of Floyd was $\sim 25 \mathrm{hPa}$ too weak in the initial conditions, but this did not appear to have a negative impact on the heavy precipitation during the simulated ET event in that study. Klein et al. (2002) use Navy Operational Global Atmospheric Prediction System $1^{\circ}$ latitude-longitude analyses to initialize numerical simulations of the ET of Typhoon Bart in 1999. The TC in these analyses consists of synthetic vertical profiles of standard meteorological variables, which are based on a simple symmetric Rankine vortex. Numerical simulations of the ET of Hurricane Irene in 1999 (Agusti-Panareda et al. 2004) were initialized from UKMET analyses, which also contain synthetic TC observations, as discussed earlier. Representation of the TC using synthetic observations on rather coarse grid domains seems to be sufficient for conduct-

\footnotetext{
${ }^{1}$ Vortex relocation is used in the GFS whereby the forecast of the storm from a previous run of the model is simply relocated to the observed storm position. The relocated vortex is typically weaker but larger than a synthetically inserted one.
} 
ing meaningful simulations and sensitivity studies in these studies.

Numerical sensitivity studies of hurricanes interacting with various idealistic midlatitude trough and environmental wind shear patterns (characteristic of ET) have been investigated by Frank and Ritchie (1999) and by Kimball and Evans (2002) using synthetic TC vortices in the initial conditions, with positive results. In a study by Ritchie and Elsberry (2001), the initial TC vortex for the numerical model is spun up from a quiescent environment to an intensity of a category-3 hurricane. This served as the pretransition storm vortex that was inserted into various idealistic environmental wind patterns to simulate ET. This approach was successful in reproducing cloud and rainfall patterns of observed storms in similar environments.

More recently, Fogarty et al. (2006) and McTaggartCowan et al. (2006) have successfully simulated the landfall of Hurricane Juan in 2003, and the eventual extratropical transition over eastern Canada, by directly inserting a synthetic hurricane vortex into the large-scale analysis fields. These hindcasts were a significant improvement over global numerical forecasts not employing vortex insertion.

\section{b. Case overview}

On 17 October 2000 meteorologists at the Meteorological Service of Canada (MSC) and the Canadian Hurricane Centre (CHC) were monitoring the development of Hurricane Michael some $500 \mathrm{~km}$ westsouthwest of Bermuda. The large-scale atmospheric flow suggested that the hurricane would move northeastward toward eastern Nova Scotia or Newfoundland and would require the issuance of forecast bulletins and warnings by the $\mathrm{CHC}$.

While the $\mathrm{CHC}$ began issuing warnings on the storm, the weather research group at the MSC was considering Michael as a candidate storm for a research aircraft mission. Plans to conduct such a flight had been in the works prior to the formation of Michael in order to gather data and gain insight into the structural changes taking place in storms undergoing ET. On 18 October a mission was arranged by the MSC in partnership with the Canadian National Research Council (NRC) to fly the Convair-580 aircraft (owned and operated by the NRC) into Hurricane Michael southeast of Nova Scotia. A summary of the research mission and the meteorological data that were collected is discussed by Abraham et al. (2004).

Almost 6 yr after the storm, we have returned to this case from a numerical modeling standpoint. The primary focus of this work is to simulate the evolution of Hurricane Michael with the Mesoscale Compressible
Community (MC2) model (Benoit et al. 1997) to demonstrate how the simple insertion of a synthetic TC vortex (consistent with observed location, intensity, and size) into the model initial conditions (Davidson et al. 1993) prior to the onset of ET leads to an improved hindcast of the event. The model is initiated using only observational data ( $\sim 24 \mathrm{~h}$ prior to landfall) that would have been available in real time, as if being run in forecast mode. Furthermore, we use the model to diagnose structural changes in the storm during ET, compare the results with aircraft data and surface meteorological observations, and test the sensitivity of the transition to various controllable parameters.

The specific operational forecast challenge with the extratropically transitioning Hurricane Michael was determining whether the hurricane, or a new baroclinic (i.e., frontal) cyclone north of the hurricane, would become the dominant storm center as the ET event unfolded. Unfortunately, operational weather forecasters at the $\mathrm{CHC}$ did not have much information in terms of high-resolution numerical guidance at the time. The Canadian Global Environmental Multiscale (GEM) forecast model (the primary weather forecast model in Canada) incorrectly developed the new baroclinic cyclone because the hurricane (which in reality became the dominant storm center early on in the transition) was poorly represented in the initial conditions. Furthermore, the GEM model at the time only had a horizontal resolution of $24 \mathrm{~km}$ in its high-resolution window, which is insufficient for modeling hurricanes.

The situation is summarized below in a quote from the forecast bulletin issued at 1200 UTC 19 October 2000 by the CHC:

THE NEW BAROCLINIC LOW HAS APPEARED AROUND 05Z AND IS INTENSIFYING RAPIDLY. AT 09Z IT WAS LOCATED BETWEEN BUOY 44142 AND THE NOVA SCOTIA COAST. THE TWO SYSTEMS WILL EVENTUALLY MERGE INTO AN INTENSE MID-LATITUDE LOW. THE PROBLEM REMAINS WHERE THE MERGER WILL TAKE PLACE AND WHICH SYSTEM WILL BECOME DOMINANT.

Late in the morning of 19 October it became apparent to forecasters that the hurricane would remain the dominant circulation center as the lows merged, but there was still considerable uncertainty about how the storm was going to evolve during its approach to Newfoundland. These issues resulted in only a short forecast lead time for severe conditions in southern Newfoundland. It will become apparent in this paper how the mesoscale modeling approach with synthetic vortex insertion would provide useful guidance if run in a forecast setting for this event. 
The remainder of this paper is organized as follows. In section 2 we give a synoptic summary of Hurricane Michael. In section 3 we describe the modeling system with grid configurations and in section 4 results from the control experiments will be given. Results from a series of sensitivity experiments are discussed and compared with operational forecast models in section 5, and a summary of the results with concluding remarks appears in section 6 .

\section{Synoptic history of Hurricane Michael}

Hurricane Michael originally formed from an extratropical low pressure system to the southwest of Bermuda from 12 to 15 October 2000, as described in detail by Davis and Bosart (2003). At 1200 UTC 15 October, the large cyclonic system had developed organized convection near its center and was declared a subtropical depression by the NHC. A day and a half later at 0000 UTC 17 October it was designated as Tropical Storm Michael and by 1800 UTC 17 October Michael had reached hurricane strength with maximum sustained winds near $33 \mathrm{~m} \mathrm{~s}^{-1}$ (65 kt). A complete storm track with sea surface temperatures (SSTs) valid at 0000 UTC 19 October is shown in Fig. 1 and a time trace plot of the "best track" (BT) (Stewart 2000) data is shown in Fig. 2. The tracking data are a combination of data from Stewart (2000) with minor refinements by Abraham et al. (2004) in the vicinity of Newfoundland.

On 18 October Michael began to accelerate toward the northeast as it moved into the region of stronger environmental winds north of $30^{\circ} \mathrm{N}$. These winds caused a spreading out of high clouds to the north of Michael, as is shown in Fig. 3a. Michael reached its maximum pre-ET intensity with maximum sustained surface winds of $39 \mathrm{~m} \mathrm{~s}^{-1}$ (75 kt) at 0000 UTC 19 October (Fig. 3b). Extratropical transition began around 0000 UTC 19 October based on the cyclone phase space (Hart 2003) trajectory from the Aviation Model (AVN) analyses shown in Fig. 4. Approximately $6 \mathrm{~h}$ after the onset of ET, significant intensification took place at a rate of at least $-2 \mathrm{hPa} \mathrm{h}{ }^{-1}$ while interacting with a sharpening, negatively tilted midtropospheric trough (Fig. 3f) and a strong surface baroclinic zone (not shown). This pattern is similar to the synoptic composite of intensifying ETs shown by Hart et al. (2006). Michael was also accelerating very rapidly during this period with maximum forward translational speeds near $30 \mathrm{~m} \mathrm{~s}^{-1}$ over decreasing SSTs (see SSTs in Fig. 1). The storm made landfall at 2230 UTC 19 October on the south coast of Newfoundland with maximum sustained winds near $39 \mathrm{~m} \mathrm{~s}^{-1}(75 \mathrm{kt})$. At that time, the storm was rapidly losing its tropical characteristics, as

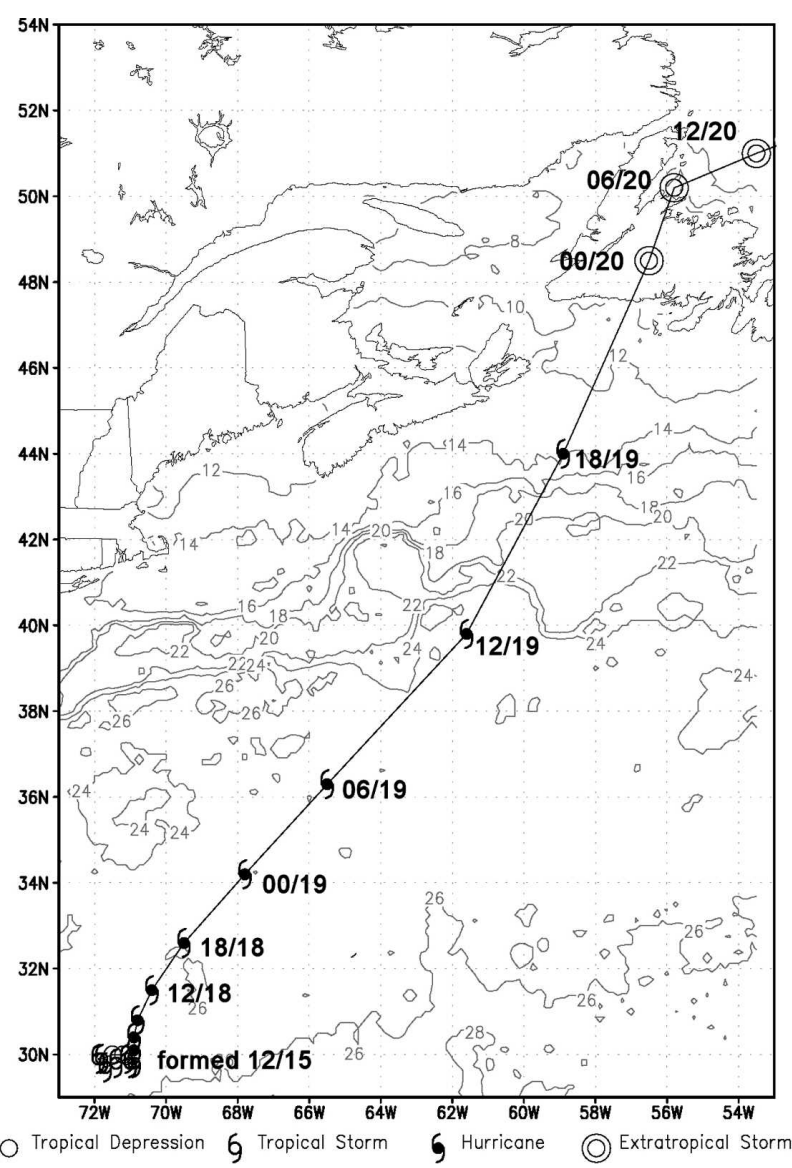

FIG. 1. Storm track (best track) for Hurricane Michael with SSTs valid at 0000 UTC 19 Oct (every $2^{\circ} \mathrm{C}$ ). Times shown are of the form hour (hh; UTC)/day (dd).

evidenced in the satellite imagery in Fig. 3 and the cyclone phase space (CPS) in Fig. 4. The NHC had declared Michael as extratropical at 0000 UTC 20 October, consistent with the CPS diagram showing the crossover time from "asymmetric warm core" to "asymmetric cold core." This crossover delineates the end of ET as defined by Evans and Hart (2003). For additional synoptic information on this event, the reader is referred to Abraham et al. (2004).

The life cycle of the baroclinic low introduced in the previous section began around 0600 UTC 19 October approximately $200 \mathrm{~km}$ south of Cape Sable, Nova Scotia. A subjective (i.e., manually drawn) sea level pressure analysis of the hurricane and this baroclinic low at 1200 UTC 19 October is shown in Fig. 5. The key to identifying a circulation in that region came from a weather buoy (44142), which showed light southwest winds just south of the estimated center of the low in Fig. 5. The low tracked toward the northeast initially, then toward the east after 1200 UTC 19 October. By 1800 UTC 19 October the sea level pressure center of 


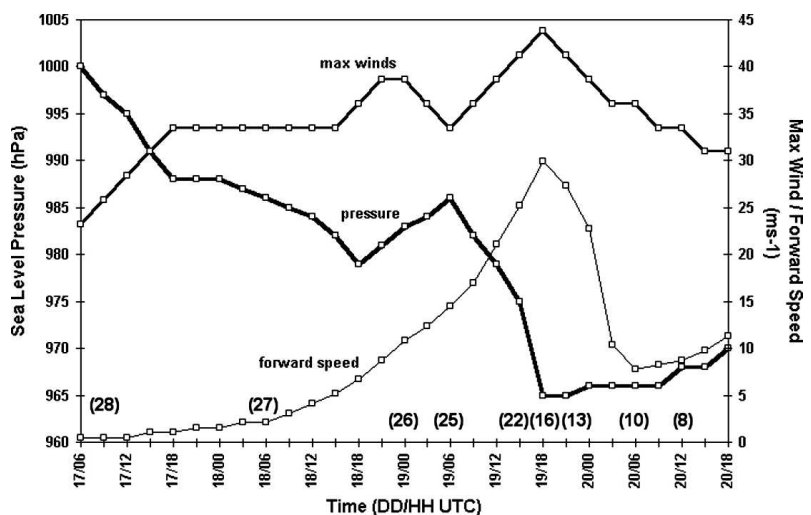

FIG. 2. Time series history for Hurricane Michael: MSLP (hPa, thick line), maximum sustained wind speed $\left(\mathrm{m} \mathrm{s}^{-1}\right.$, medium line), and storm forward speed ( $\mathrm{m} \mathrm{s}^{-1}$, thin line). Values in parentheses at the bottom of the plot indicate SSTs $\left({ }^{\circ} \mathrm{C}\right)$ beneath the storm center.

the baroclinic low (indicating the surface circulation) was becoming less distinct while the primary circulation became centered at the location of the hurricane. In section 4 we will discuss the evolution of this low in more detail.

\section{Description of the modeling system}

\section{a. The mesoscale atmospheric model}

The MC2 model, version 4.9.6, is used to conduct experiments simulating Hurricane Michael using a synthetic TC vortex insertion in the initial conditions. This nonhydrostatic, fully compressible limited-area model employs three-dimensional semi-Lagrangian advection and semi-implicit time discretization to solve the primitive Euler equations on terrain-following height coordinates (Gal-Chen and Somerville 1975). Version 4.0 of the Canadian Meteorological Centre (CMC) Physics Library is used for the parameterization of the physical processes. A kinetic energy closure scheme described by Benoit et al. (1989) is employed in the boundary layer to parameterize turbulent transports. MoninObukhov similarity theory (Monin and Obukhov 1954) is used in the atmospheric surface layer to determine the vertical profile of the wind field and sea surface fluxes. Standard bulk formulations are used to represent turbulent fluxes of momentum, sensible heat, and latent heat at the lower boundary. The wind, temperature, and humidity values used to compute these fluxes are taken from the lowest computational level in the model. The force-restore surface scheme (Benoit et al. 1989) is used in all simulations to predict the surface temperature and moisture budget over land. Deep convective processes are handled with the Kain and Fritsch
(1990) convective parameterization in the control simulations on the coarser $(12 \mathrm{~km})$ grid, but solved explicitly on the fine $(3 \mathrm{~km})$ grid, described below. Shallow convective processes are solved explicitly in all of the experiments. Stratiform condensation (cloud microphysical) schemes are given by Tremblay et al. (1996) for the 12-km simulations and Kong and Yau (1997) for the $3-\mathrm{km}$ runs. For a general overview of the model, see Benoit et al. (1997).

Grid configurations and model integration periods are shown in Fig. 6. The model is piloted (forced at the lateral boundaries) by regional analyses every $6 \mathrm{~h}$ from the CMC Data Assimilation System archive (Chouinard et al. 1994) on a $28-\mathrm{km}\left(0.25^{\circ}\right)$ latitude-longitude grid covering eastern North America and the western Atlantic Ocean $\left(20.0^{\circ}-70.0^{\circ} \mathrm{N}\right.$ and $\left.100.0^{\circ}-30.0^{\circ} \mathrm{W}\right)$. Integrations of the model are run on three different grids. Two of the grids (one large and one small) have a horizontal resolution of $12 \mathrm{~km}\left(0.108^{\circ}\right)$ while the third has a horizontal resolution of $3 \mathrm{~km}\left(0.027^{\circ}\right)$. The large 12 $\mathrm{km}$ latitude-longitude grid extends from $21.3^{\circ}$ to $64.5^{\circ} \mathrm{N}$ and from $88.2^{\circ}$ to $35.8^{\circ} \mathrm{W}$ with 25 computational levels [7 in the atmospheric boundary layer (BL)]. The smaller $12-\mathrm{km}$ grid spans from $25.4^{\circ}$ to $54.6^{\circ} \mathrm{N}$ and from $78.2^{\circ}$ to $45.8^{\circ} \mathrm{W}$ with the same number of computational levels. The finest grid at $3-\mathrm{km}$ resolution includes Nova Scotia and Newfoundland from $36.2^{\circ}$ to $49.7^{\circ} \mathrm{N}$ and from $65.7^{\circ}$ to $52.2^{\circ} \mathrm{W}$ with 40 computational levels (12 in the $\mathrm{BL}$ ). The lowest computational level in the $3-\mathrm{km}$ grid is $40 \mathrm{~m}$. A time step of $120 \mathrm{~s}$ is used on the $12-\mathrm{km}$ domains and $30 \mathrm{~s}$ for the $3-\mathrm{km}$ domain.

\section{b. The synthetic storm vortex}

The initial atmospheric fields are modified by inserting a synthetic TC vortex constructed prior to running the model. ${ }^{2}$ The poorly analyzed hurricane in the original fields is very near the location where we insert the synthetic vortex, so the original low is completely replaced. The vortex is constructed using key observational data from the NHC best track (Stewart 2000) and from NHC operational message archives (available online at http://www.nhc.noaa.gov/archive/2000/ MICHAEL.html). Control parameters for the vortex include (a) minimum central sea level pressure, (b) storm center position, (c) size (radius of $15 \mathrm{~m} \mathrm{~s}^{-1}$ surface winds, $R_{15}$ ), and (d) percent of the background flow used for the initial wind field asymmetry. The sea level pressure profile follows that of Fujita (1952) and is defined as a function of radius:

\footnotetext{
${ }^{2}$ This synthetic vortex is very similar to the one used in the TC-LAPS (section 1) and is described by Davidson et al. (1993).
} 

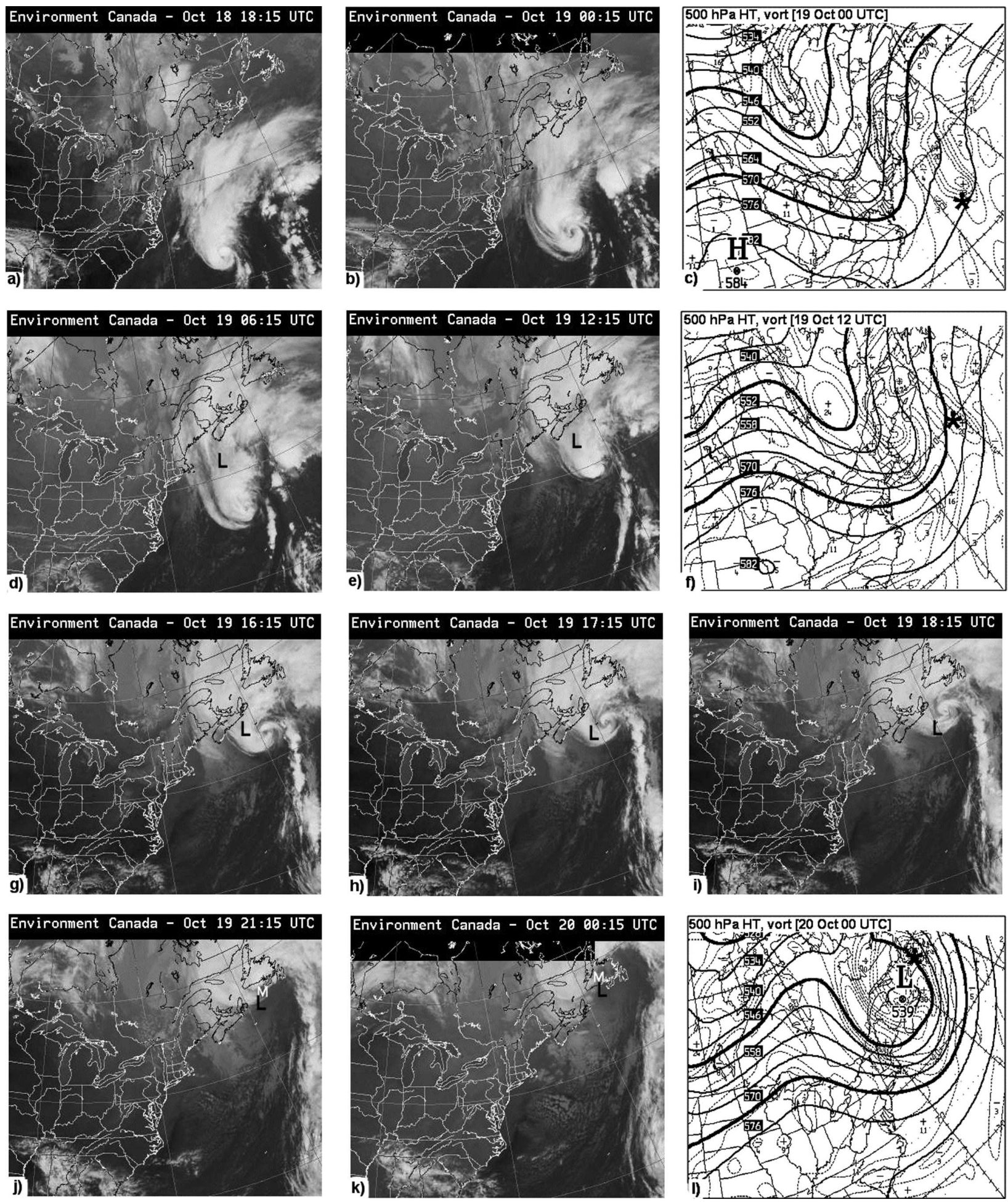

FIG. 3. Evolution of Geostationary Operational Environmental Satellite infrared imagery, and 500-hPa geopotential height and absolute vorticity analyses during the extratropical transition of Hurricane Michael, October 2000. The location of Michael in the satellite images is marked with a white $\mathrm{M}$ where not obvious, and the baroclinic low with a black $\mathrm{L}$. The location of the hurricane surface center in the 500-hPa panels is shown by the large black asterisk. 


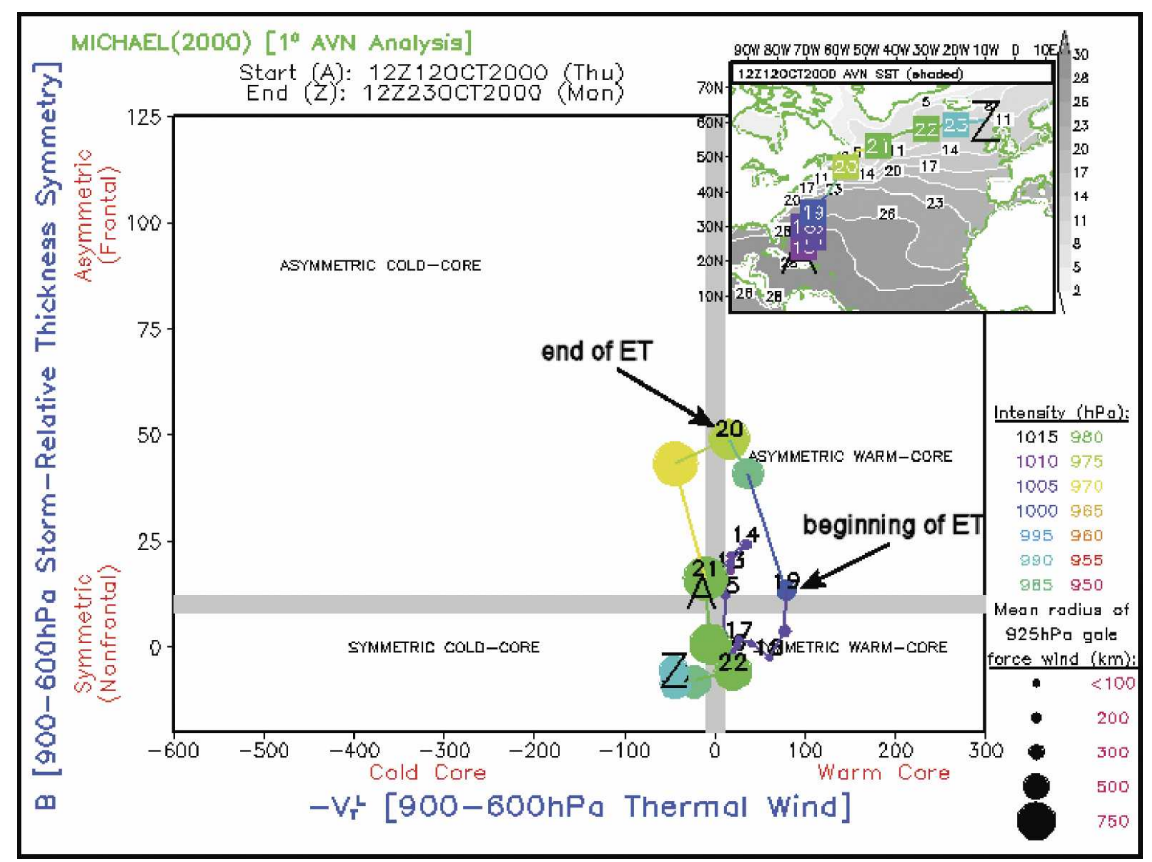

FIG. 4. Hurricane Michael's ET as represented within CPS using $1^{\circ}$ AVN analyses. The ordinate indicates the storm symmetry $(B)$ while the abscissa is a measure of the cold/warm core structures of the system (rhs of diagram corresponds to $-\left|\mathbf{V}_{T}^{L}\right|>0$ for warm core) as described in Hart (2003). Time moves forward from A to Z, the start and end of the cyclone life cycle resolvable within the available dataset and its geographic boundaries. The size of the cyclone (mean radius of the $925-\mathrm{hPa}$ gale force winds) corresponds to the size of the solid circles along the phase trajectory (largest shown is approximately $750 \mathrm{~km}$ ). Circle color corresponds to the intensity of the cyclone, with purple for the weaker end of the scale and green for the more intense. The track of the cyclone is plotted in the inset, with the date marked at the 0000 UTC positions.

$$
p(r)=p_{e}-d p\left[1+\left(\frac{r}{R_{o}}\right)^{2}\right]^{-(1 / 2)}
$$

where $d p=p_{e}-p_{c}\left(p_{e}\right.$ is the ambient sea level pressure and $p_{c}$ is the minimum sea level pressure in the storm). Here, $R_{o}$ is the characteristic radius (smaller $R_{o}$ yields a larger radial pressure gradient). For example, for a given $d p$, if $R_{15}$ is decreased to give a compact storm, then $R_{o}$ will also decrease. The moisture structure of the vortex is cylindrically symmetric about the storm center and defined by a moist adiabat that extends from $1000 \mathrm{hPa}$ (with corresponding environmental temperature for that level) to a level where that moist adiabat intersects the environmental temperature sounding, which defines the cloud top. The relative humidity throughout the storm core is near $90 \%$. The environmental parameters (including temperature) are obtained from an annular region with an inner radius of $R_{15}$ and an outer radius of $2 R_{15}$. This annulus is essentially the same annulus used as the blending zone for which the vortex is inserted into the environmental fields. This approach has been used for numerical studies of Hurricane Juan in 2003 by McTaggart-Cowan et al. (2006) and by Fogarty et al. (2006).

The initialization procedure described above is applied at 0000 UTC 19 October to the $12-\mathrm{km}$ grids. This initial time was chosen when Michael was at its most developed pretransition stage (Fig. 3b). It is important to apply the insertion before the onset of ET because the technique is most appropriate for hurricanes with a generally symmetric moisture structure, although we recognize that there are invariably some asymmetric features in all TCs. After the $12-\mathrm{km}$ simulation is completed, a second integration on the 3-km grid (using output from the $12-\mathrm{km}$ grid starting at 1200 UTC 19 October) is run for $18 \mathrm{~h}$. The initial time of the $3-\mathrm{km}$ simulations is $12 \mathrm{~h}$ after the vortex insertion, which appears to be a suitable time for the model to "adjust" to the hurricane (e.g., spurious behavior in wind and pressure fields ceases after a few hours of integration). The boundary conditions for the inner domain are updated every $30 \mathrm{~min}$ with output from the $12-\mathrm{km}$ do- 


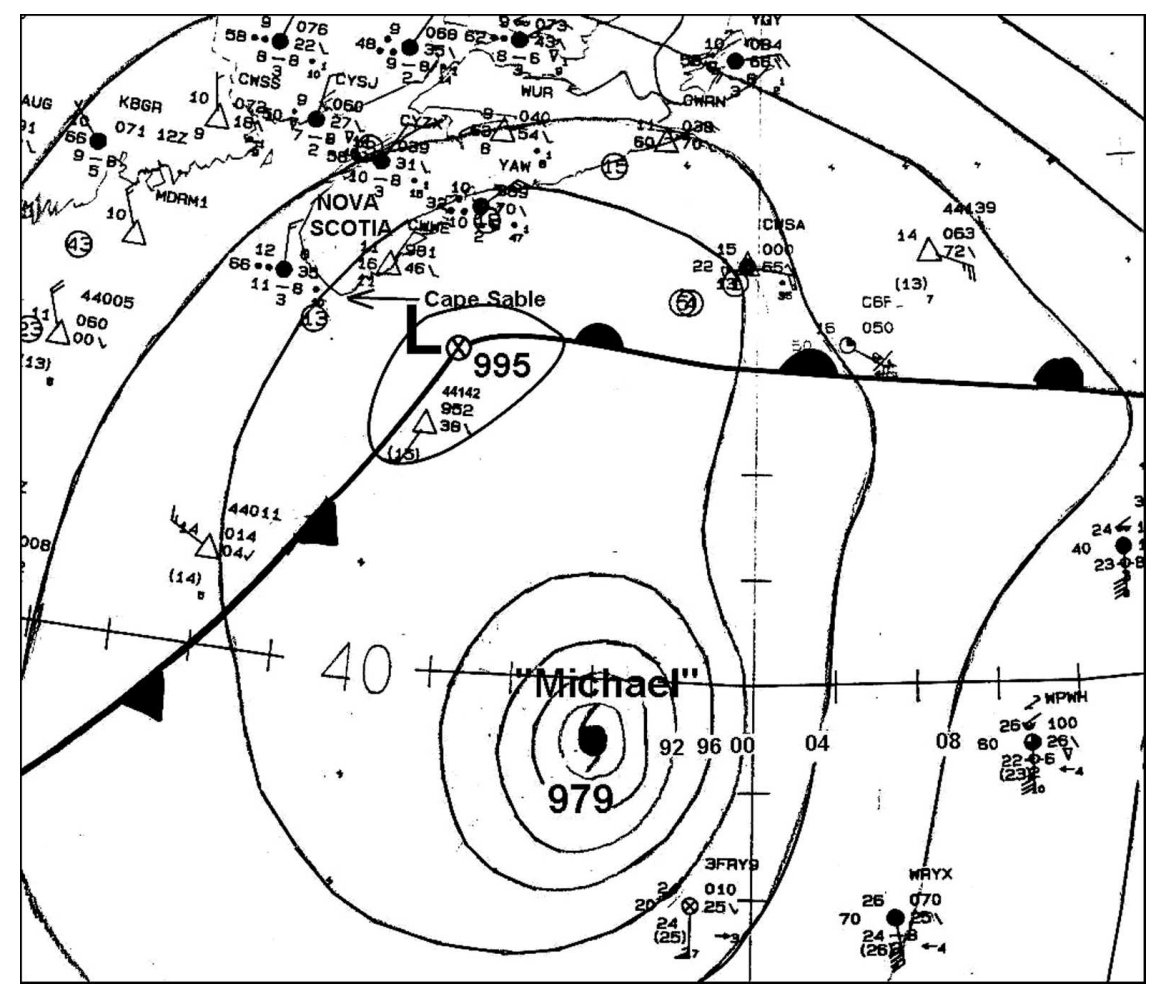

FIG. 5. Manually drawn (subjective) SLP analysis (contours every $4 \mathrm{hPa}$ ) of Hurricane Michael and the baroclinic cyclone at 1200 UTC 19 Oct. Standard synoptic weather data plots are also shown.

main. ${ }^{3}$ To reduce the possibility of "shocking" the model, we implant the synthetic vortex into the $12-\mathrm{km}$ grid instead of the $3-\mathrm{km}$ grid. This is also a desirable approach since the effects of the storm on the larger scale are resolved on the larger grid, which drives the $3-\mathrm{km}$ grid used for resolving the details of the storm structure.

\section{Control simulations}

\section{a. No-vortex simulation}

We start by conducting a no-vortex simulation of this event (hereafter called NOVOR) on the "small" 12-km grid (see Fig. 6) beginning at 0000 UTC 19 October with a 42-h integration length ending at 1800 UTC 20 October and piloted by CMC analyses. We compare this with output from the regional GEM model forecasts for the same period. The GEM model had a horizontal resolution of $24 \mathrm{~km}$ at the time of this event and was one of the primary sources of numerical guidance

\footnotetext{
${ }^{3} \mathrm{MC} 2$ is set up for one-way nesting only (from the outer domain to the inner domain).
}

for weather forecasters during the storm. We will refer to this hereafter as GEM24.

With its relatively coarse resolution and scarcity of hurricane observations in the initial conditions, GEM24 simply forecast a trough of low pressure at the location of Hurricane Michael. The model developed a baroclinic low south of Nova Scotia (the same low introduced earlier) and tracked it toward southwestern Newfoundland as shown in Fig. 7. The NOVOR simulation yielded a similar solution (see Fig. 7) with the baroclinic low being the dominant cyclone; however, the model did generate a weaker low in the location of Hurricane Michael (not shown; this low was much too weak to be considered an adequate representation of the hurricane and tracked too far to the east over the Avalon Peninsula in eastern Newfoundland). Also in Fig. 7 we show the subjectively analyzed track of the baroclinic low for comparison (taken from Abraham et al. 2004).

The important difference between the observed track of the baroclinic low compared with the model results is that the observed low moves eastward between 1200 and 1800 UTC 19 October while the GEM24 and NOVOR model runs show a motion toward the north- 

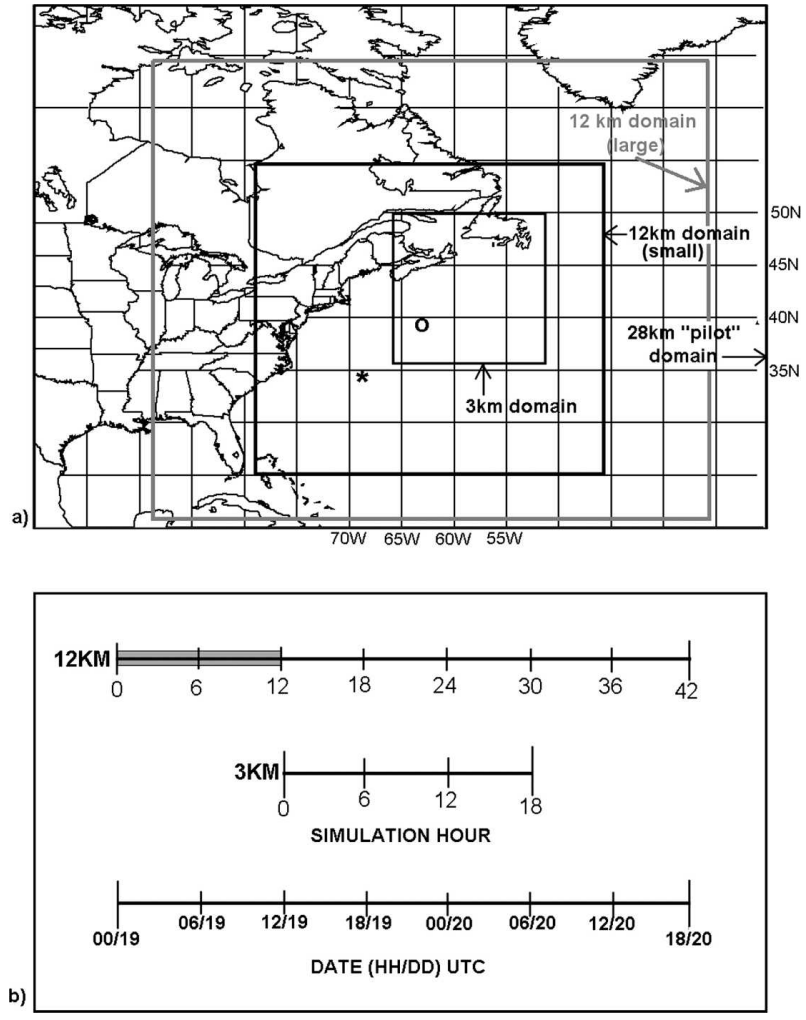

FIG. 6. Layout for the model experiments: (a) grid configurations and (b) timelines for the model integrations. The asterisk in (a) marks the storm center at hour zero of the $12-\mathrm{km}$ control simulations and the open circle marks the mean position of the storm at hour zero of the $3-\mathrm{km}$ control simulations. The gray region on the 12-km timeline in (b) denotes the 12-h model adjustment period.

east close to the coast of Nova Scotia. This eastward motion occurs when the low becomes incorporated into the circulation of the hurricane; this was not captured by the GEM model. Surface weather data described by Abraham et al. (2004) suggest that the low may not have completely merged with the center of the hurricane (indicated by the northward turn in the track in Fig. 7); however, it was clear that the hurricane became the dominant cyclone during the morning and afternoon of 19 October 2000.

\section{b. Vortex-initiated control simulations}

The control simulation for this event is one that applies the vortex insertion technique described in section 3 . There are actually two control simulations: one on the small 12-km grid, which we call MICH12, and a second on the fine 3-km grid, which we call MICH3. For these runs, 14-km SST data from the National Environmental Satellite, Data, and Information Service (NESDIS) valid at 0000 UTC 19 October are used for

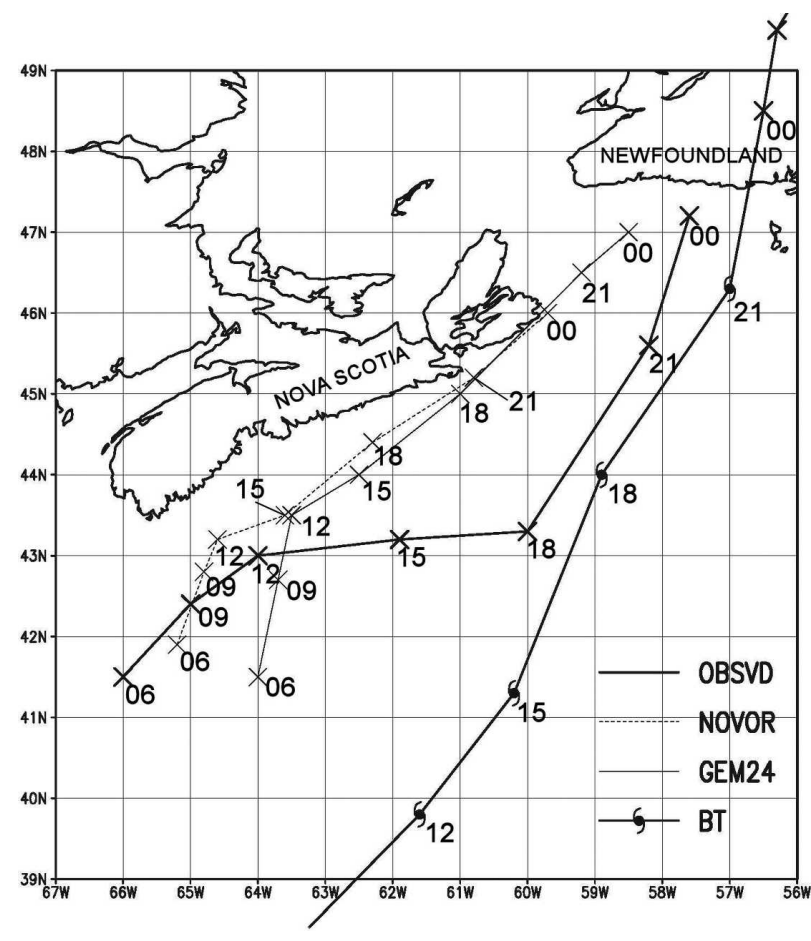

FIG. 7. Tracks of the baroclinic cyclone center from observations (OBSVD), the operational GEM model (GEM24), and the no-vortex version of the MC2 model (NOVOR) every $3 \mathrm{~h}$ from 0600 UTC 19 Oct to 0000 UTC 20 Oct. The BT segment during the period of interest is also plotted. The valid time for the storm positions in UTC is indicated to the lower right of the position markers.

the model ocean surface boundary condition. The SST remains fixed during the model integrations. The data are obtained from the NESDIS Web site (http:// www.nesdis.noaa.gov/) and are mapped to the piloting domain in Fig. 6a.

Simulated storm tracks are shown in Fig. 8a for MICH12 and in Fig. 8b for MICH3 including results from runs that use climatological SST (CLIM) at the lower boundary, which will be discussed briefly in section 5. Table 1 includes the vortex and model specifications for the $12-\mathrm{km}$ control run. The remaining contents of the table refer to the ensemble system to be discussed in section 5. The overall track prediction is very good. The location of landfall is within $50 \mathrm{~km}$ of the actual landfall for both the 12- and 3-km runs. The timing of landfall is only $1-1.5 \mathrm{~h}$ later than reality. The model reproduces the deceleration of the storm after landfall with an eastward motion during the day on 20 October as it was drifting with the deep-layered low shown in Fig. 31.

Figure 9 displays time traces of minimum sea level pressure (MSLP), maximum surface wind (MSW) speed, and SST beneath the storm center for the 

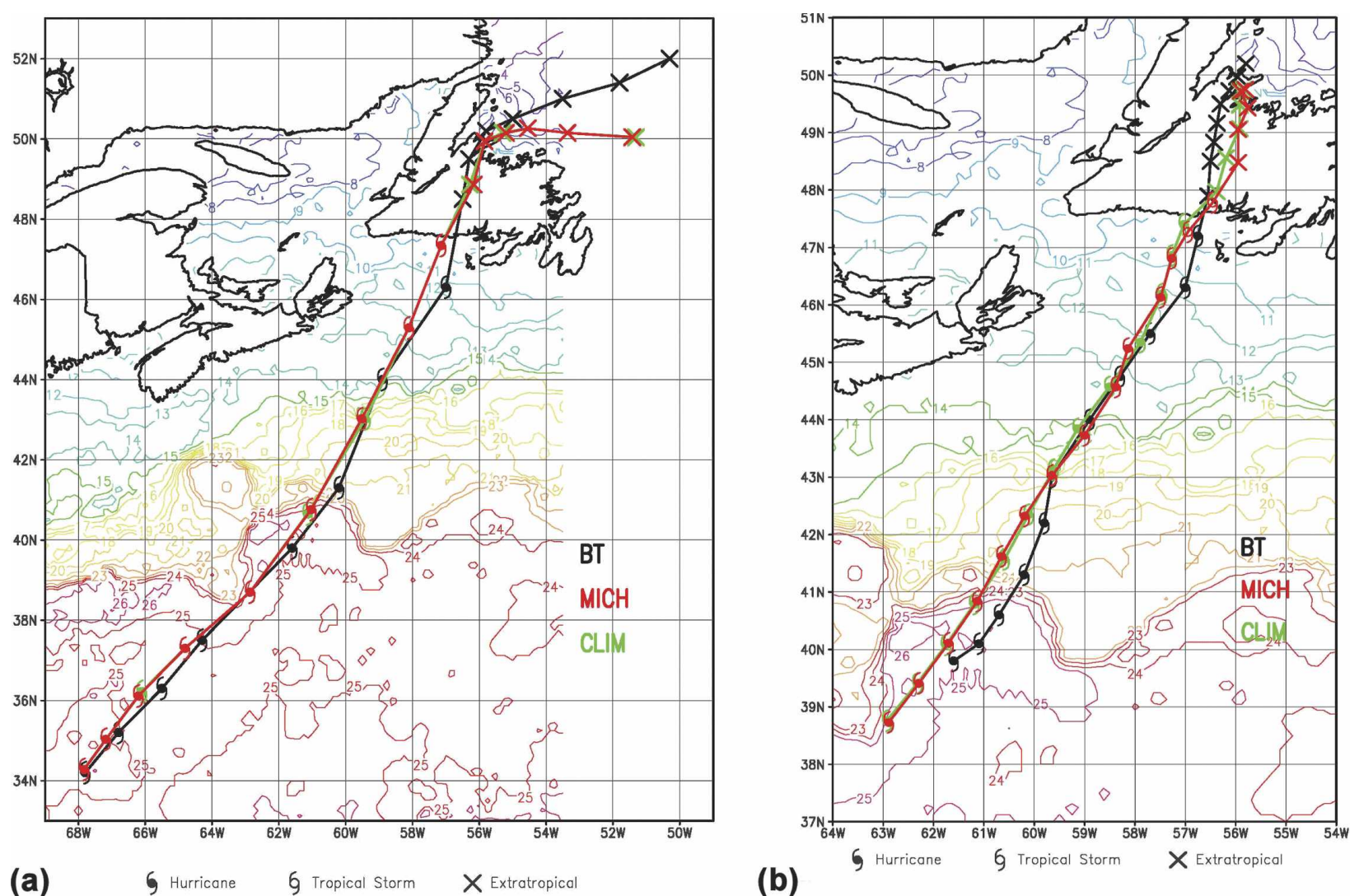

FIG. 8. (a) Storm tracks from the 12-km control, and (b) 3-km control runs of the model. Black trajectories denote the BT, red trajectories denote the observed-SST control run, and green is the climatology SST storm track. Track nodes are every $3 \mathrm{~h}$ in (a) from 0000 UTC 19 Oct to 1800 UTC 20 Oct and every $1 \mathrm{~h}$ in (b) from 1200 UTC 19 Oct to 0600 UTC 20 Oct. Observed (NESDIS) SST (every $\left.1^{\circ} \mathrm{C}\right)$ is also shown.

MICH12 and MICH3 simulations including the best track. ${ }^{4}$ Before proceeding, we clarify that when referring to the best track, MSW is defined as the maximum 1-min mean (sustained) winds anywhere in the storm at $10 \mathrm{~m}$ above the surface (either estimated from satellite imagery or measured by aircraft). When referring to output from the model, MSW is the maximum instantaneous (e.g., snapshot) surface wind anywhere in the storm, where "surface" is defined at the $60-\mathrm{m}(40 \mathrm{~m})$ (e.g., lowest computational) level in the $12-\mathrm{km}(3 \mathrm{~km})$ simulations. Simulation hour 0 in Figs. 9a-c corresponds to the time of synthetic vortex insertion. Focusing first on the MICH12 results, we see that the model tends to deepen the storm from the start when in reality it weakened before undergoing rapid intensification after $6 \mathrm{~h}$ (0600 UTC 19 October). Given that the model

\footnotetext{
${ }^{4}$ Note that the best track is not exact; i.e., it is an estimate with inherent uncertainties on the order of approximately $\pm 2.5 \mathrm{~m} \mathrm{~s}^{-1}$ for MSW and approximately $\pm 4 \mathrm{hPa}$ for MSLP throughout the life cycle of the storm.
}

requires approximately $12 \mathrm{~h}$ to adjust to the new initial conditions, we generally do not put much faith in the early part of the simulation. The model deepens the storm over the cooler waters and successfully represents the storm-central sea level pressure just prior to landfall. The modeled storm continues deepening to just below $960 \mathrm{hPa}$ after landfall ( $\sim 5 \mathrm{hPa}$ deeper than reality); however, the MSW is quite close to the observed winds during that period.

Results from the MICH3 control are also shown in Figs. 9a-c. One noticeable difference from MICH12 is that the MSW reaches $52 \mathrm{~m} \mathrm{~s}^{-1}(100 \mathrm{kt})$ in $\mathrm{MICH} 3$ compared with $47 \mathrm{~m} \mathrm{~s}^{-1}$ (91 kt) in MICH12. Both are overestimates of the observed MSW, which was near 44 $\mathrm{m} \mathrm{s}^{-1}(85 \mathrm{kt})$. Regardless, this is much better than the NOVOR run, which generated maximum winds of only $28 \mathrm{~m} \mathrm{~s}^{-1}$ (55 kt) at that time (not shown).

\section{c. Impact of vortex insertion}

We now examine the impact of employing the vortex insertion method in the model initial conditions com- 
TABLE 1. List of experiments used in the study with the 12-km grid. MICH12 is the control run using 19 October observed SST surface boundary condition. MICH_GSM and MICH_GLG are the experiments whose lateral boundaries are driven by GEM output fields. Minimum sea level pressure is MSLP, lat-lon indicate the storm center position, R15 is the radius of $15 \mathrm{~m} \mathrm{~s}^{-1}$ winds, basicp is the fraction of the background flow used to prescribe the initial wind field asymmetry, convec is the convective parameterization scheme, comp_levs indicates the number of computational levels in the model (where the number in parentheses indicates the number of levels in the boundary layer), and stcond is the stratiform condensation scheme. Numerical schemes: Kain-Fritsch (Kfc), Fritsch-Chappel (Fcp), Kuo (Kuo), Tremblay (Exc), and Kong-Yau (Excrig); see text for details. Changed parameters in each experiment are in boldface.

\begin{tabular}{lcccccccc}
\hline \hline \multicolumn{1}{c}{ Expt } & SLP $(\mathrm{hPa})$ & Lat $\left({ }^{\circ} \mathrm{N}\right)$ & Lon $\left({ }^{\circ} \mathrm{W}\right)$ & R15 $(\mathrm{km})$ & Basicp $(\mathrm{frac})$ & Convec & Comp_levs & Stcond \\
\hline MICH & 983 & 34.2 & 67.8 & 320 & 0.50 & Kfc & $25(7)$ & Exc \\
MICH_GSM & 983 & 34.2 & 67.8 & 320 & 0.50 & Kfc & $25(7)$ & Exc \\
MICH_GLG & 983 & 34.2 & 67.8 & 320 & 0.50 & Kfc & $25(7)$ & Exc \\
EM1 & 983 & 34.2 & 67.8 & 320 & $\mathbf{0 . 2 5}$ & Kfc & $25(7)$ & Exc \\
EM2 & 983 & 34.2 & 67.8 & 320 & $\mathbf{0 . 7 5}$ & Kfc & $25(7)$ & Exc \\
ES1 & 983 & 34.2 & 67.8 & $\mathbf{2 9 0}$ & 0.50 & Kfc & $25(7)$ & Exc \\
ES2 & 983 & 34.2 & 67.8 & $\mathbf{3 8 0}$ & 0.50 & Kfc & $25(7)$ & Exc \\
ES3 & 983 & 34.2 & 67.8 & $\mathbf{4 3 0}$ & 0.50 & Kfc & $25(7)$ & Exc \\
EI1 & $\mathbf{9 7 9}$ & 34.2 & 67.8 & 320 & 0.50 & Kfc & $25(7)$ & Exc \\
EI2 & $\mathbf{9 8 7}$ & 34.2 & 67.8 & 320 & 0.50 & Kfc & $25(7)$ & Exc \\
EP1 & 983 & 34.2 & $\mathbf{6 8 . 4}$ & 320 & 0.50 & Kfc & $25(7)$ & Exc \\
EP2 & 983 & $\mathbf{3 4 . 9}$ & 67.8 & 320 & 0.50 & Kfc & $25(7)$ & Exc \\
EP3 & 983 & 34.2 & $\mathbf{6 7 . 1}$ & 320 & 0.50 & Kfc & $25(7)$ & Exc \\
EP4 & 983 & $\mathbf{3 3 . 6}$ & 67.8 & 320 & 0.50 & Kfc & $25(7)$ & Exc \\
EC1 & 983 & 34.2 & 67.8 & 320 & 0.50 & Fcp & $25(7)$ & Exc \\
EC2 & 983 & 34.2 & 67.8 & 320 & 0.50 & Kuo & $25(7)$ & Exc \\
ER1 & 983 & 34.2 & 67.8 & 320 & 0.50 & Kfc & $\mathbf{3 2 ( 1 0 )}$ & Exc \\
EQ1 & 983 & 34.2 & 67.8 & 320 & 0.50 & Kfc & $25(7)$ & Excrig \\
\hline
\end{tabular}

pared with the no-vortex simulation discussed in section 4a. Fields of sea level pressure at 0000 UTC 20 October (24-h prediction) are shown in Fig. 10 for GEM24, NOVOR, and MICH12, and are compared with a manually drawn sea level pressure analysis (Fig. 10a). The NOVOR and GEM24 solutions clearly fail to capture the storm structure. The NOVOR run produces the baroclinic cyclone (discussed in section 4a) of $980 \mathrm{hPa}$ just east of Nova Scotia and a weak (985 hPa) cyclone moving toward the Avalon Peninsula of Newfoundland. The eastern low is the model's poor interpretation of the hurricane. The experiment employing synthetic vortex insertion (MICH12) leads to a much different solution at 0000 UTC 20 October (Fig. 10d) with a 964-hPa storm just south of Newfoundland and an area of high winds on the east side of the low. This matches reasonably well with the analysis in Fig. 10a and with wind damage reports within about $200 \mathrm{~km}$ east of landfall. The no-vortex runs fail to produce this tight wind and pressure pattern.

\section{d. Structural evolution during ET}

A manually drawn sea level pressure analysis of Hurricane Michael at maximum intensity is shown in Fig. 11a. Model-simulated sea level pressure and surface (40 $\mathrm{m})$ wind speeds from the MICH3 simulation are shown in Fig. 11b for comparison. Simulated surface temperatures $(40 \mathrm{~m})$ are shown in Fig. 11c. Generally, there is good agreement on the central pressure and overall storm circulation as depicted by the isobars-keeping in mind that the model time is $1 \mathrm{~h}$ later to account for the $\sim 1 \mathrm{~h}$ delay of the simulated storm. Although the baroclinic low (which formed south of Nova Scotia) is represented in the model, it is not as close to the center of Michael as indicated in the analysis in Fig. 11a. We should add, however, that there are not enough data to confirm the actual location of the baroclinic low in Fig. 11a. Based on the work of Abraham et al. (2004), it was speculated that the low was not far to the southwest of Michael as shown by "L?" in Fig. 11a. The trough in SLP associated with the baroclinic low extends west of Michael in the model, while it is southwest of Michael in the analysis. Despite these differences, the hurricane is the dominant cyclone in the model during the early stage of ET.

The wind field around the center of Michael in Fig. $11 \mathrm{~b}$ seems very realistic although we do not have enough surface wind observations to construct a $2 \mathrm{D}$ wind field for Fig. 11a. The MSW (at $40 \mathrm{~m}$ ) at this time is $41 \mathrm{~m} \mathrm{~s}^{-1}(80 \mathrm{kt}) 85 \mathrm{~km}$ to the south-southeast of the center. The magnitude is consistent with a ship report of $41 \mathrm{~m} \mathrm{~s}^{-1}$ measured $30 \mathrm{~m}$ above sea level approximately $20 \mathrm{~km}$ east of the storm center at 1700 UTC 19 October [keeping in mind the error in storm position is on the order of $25 \mathrm{~km}$ based on the analysis of Abraham et al. (2004, p. 1330)]. This also suggests that the 
Hurricane Michael - MSLP (12 and 3 km runs)

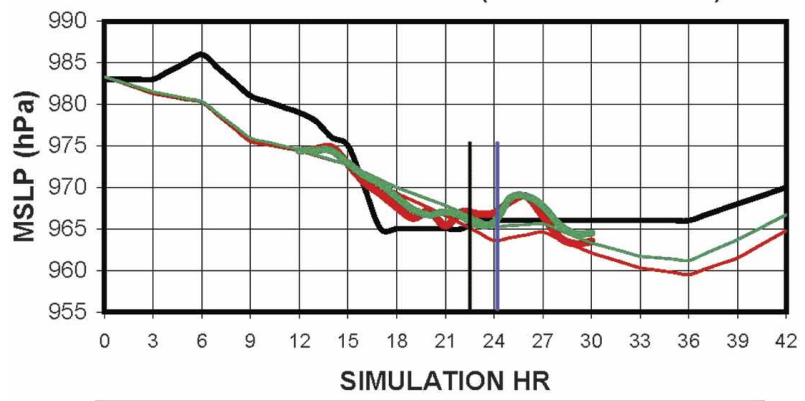

(a)

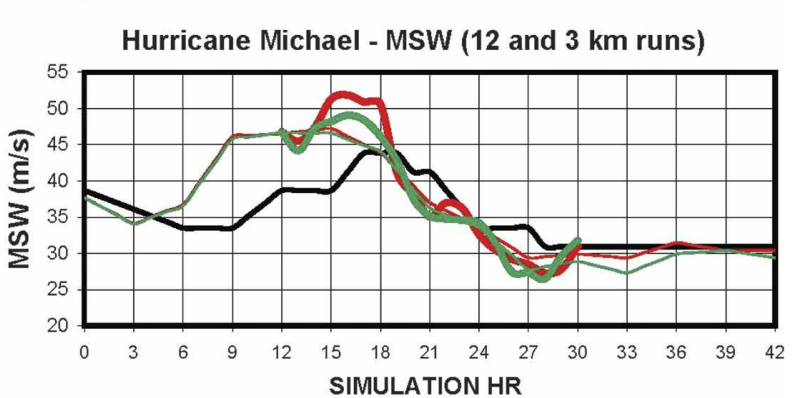

(b) -

Hurricane Michael - SST (12 and 3 km runs)

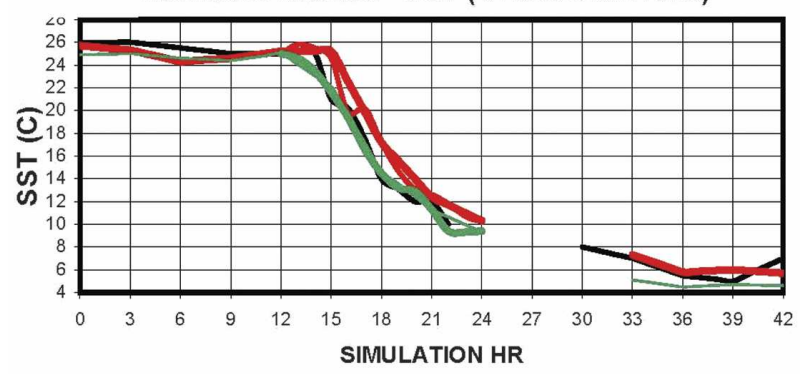

(c)

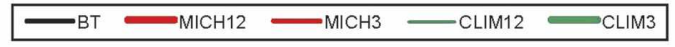

FIG. 9. Model results for the $12-\mathrm{km}$ control (MICH12 and CLIM12) and 3-km control (MICH3 and CLIM3) simulations: (a) evolution of MSLP for MICH12 (thin red line), CLIM12 (thin green line), MICH3 (thick red line), CLIM3 (thick green line) and the BT (black line); (b) MSW; and (c) SST beneath the storm center as a function of model simulation time (h). The vertical bars in (a) denote the approximate model landfall time (blue) and observed landfall time (black).

wind field was extremely "tight," which is represented in the simulation.

The presence of the significant background temperature gradient (i.e., baroclinic zone) shown in Fig. 11c highlights the extratropical nature of the environment. The warm front in the analysis in Fig. 11a is represented reasonably well in the simulation (but a bit farther north) in Fig. 11c as denoted by the tight gradient in temperature and marked in the image. The storm would be considered as purely extratropical if the tight temperature gradient (front) extended into the center (as is the case with the baroclinic low in Fig. 11c).

Vertical profiles of wind speed taken approximately $85 \mathrm{~km}$ southeast of the hurricane center from a dropsonde (launched just prior to 1700 UTC 19 October) and from the model (MICH3 at 1800 UTC 19 October) are shown in Fig. 12. The dropsonde wind data (with an absolute accuracy of $0.5-2.0 \mathrm{~m} \mathrm{~s}^{-1}$ ) were quality controlled by a specialist at the NHC (J. Franklin 2003, personal communication). For clarity, note that the horizontal distance from the launch position of the sonde and the surface center of the storm is $\sim 85 \mathrm{~km}$. The dropsonde profile exhibited the strongest low-level winds of any of the 16 sondes that were launched from the Convair-580 aircraft. The profile from the model was chosen as closely as possible to the storm-relative location of the dropsonde. The model profile was taken at 1800 versus 1700 UTC 19 October in order to account for the slower simulated motion. Nonetheless, we can see that the surface wind speeds compare rather well, and the maximum low-level wind height is near $500 \mathrm{~m}$ in both. The model is unsuccessful in replicating the extreme low-level wind shear (at the very least, finer vertical resolution would be necessary to resolve this). The model does not capture the extreme wind magnitudes between 500 and $2000 \mathrm{~m}$, which is also the case when sampling other vertical profiles from the model in the high-wind region (not shown). On the other hand, the model does indicate that strong winds extend through a deep layer of the atmosphere on the east side of the rapidly moving storm.

Vertical cross sections of equivalent potential temperature $\theta_{e}$ and horizontal wind speeds from the $\mathrm{MICH} 3$ control experiment provide a summary of the thermodynamic and dynamic changes in the storm structure during ET in Fig. 13. The cross sections run from west to east through the center of the storm along a distance of $500 \mathrm{~km}$. Figure 13a shows the structure of the initial idealized storm vortex. By 1200 UTC 19 October (Fig. 13b), ET has already begun as seen by the jet of low $-\theta_{e}$ air on the west side of the storm. Drier air also intrudes into the midlevels of the storm $(\sim 500$ $\mathrm{hPa}$ ). As ET continues, the warm core (below $500 \mathrm{hPa}$ ) changes from having a westward tilt, to an eastward tilt prior to landfall, then to a northwestward tilt after landfall. This cannot be strictly discerned from the panels in Fig. 13; however, it is clear that the deep tropospheric tilt, as a whole, is westward to northwestward, highlighting the extratropical nature of the cyclone. In addition, the strong wind jet encircling the storm contains increasingly cooler/drier air, effectively "secluding" the warm core from the cooler air mass to the north. This 

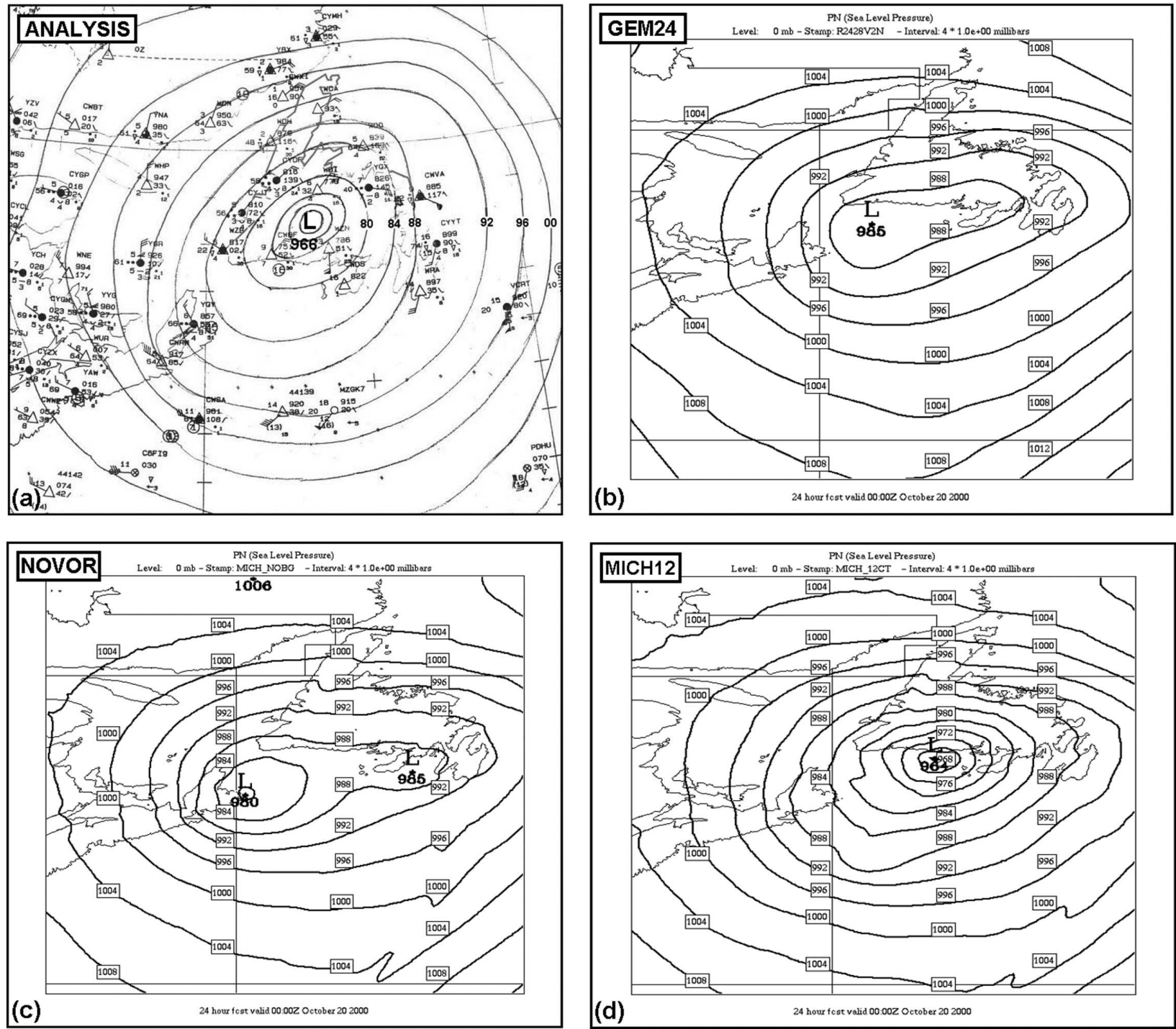

FIG. 10. SLP (every $4 \mathrm{hPa}$ ) valid at 0000 UTC 20 Oct based on (a) manually drawn (subjective) analysis, (b) 24-h GEM regional forecast, (c) 24-h "no vortex" simulation of the 12-km MC2 model, and (d) 24-h simulation of the control run of the MC2 model with vortex insertion employed (MICH12). Standard synoptic weather plots are shown in (a).

pattern was also observed in dropsonde data analyses [see the contoured lobes of air with $\theta_{e}$ less than $330 \mathrm{~K}$ in Fig. 10b of Abraham et al. (2004)]. The jet on the east side of the storm becomes elevated to near the 700-hPa level by 1900 UTC 19 October (Fig. 13d) and the warm core becomes thermodynamically decoupled from the cooler SSTs $\left(\sim 14^{\circ} \mathrm{C}\right)$ as shown by the cool $\theta_{e}$ air in the lower BL. In the hours leading up to landfall, drier air intrudes into the midlevels of the storm and destroys the upper part of it (Fig. 13e). Just prior to landfall (Fig. 13f) very low $\theta_{e}$ air $(<310 \mathrm{~K})$ floods in from the west and the storm becomes frontal, although an elevated warm core remains.

\section{Sensitivity experiments}

\section{a. Summary of the ensemble system}

An ensemble of 17 experiments is run on the 12-km grids shown in Fig. 6 for Hurricane Michael to provide a measure of the storm's sensitivity to various initial and boundary conditions, as well as model parameters. A summary of the members of the ensemble is displayed in Table 1. The control experiment piloted by CMC analyses on the small $12-\mathrm{km}$ grid is denoted by "MICH" in the table. Experiments MICH_GSM and MICH_GLG represent experiments piloted by GEM forecast fields on the small and large $12-\mathrm{km}$ grids, re- 

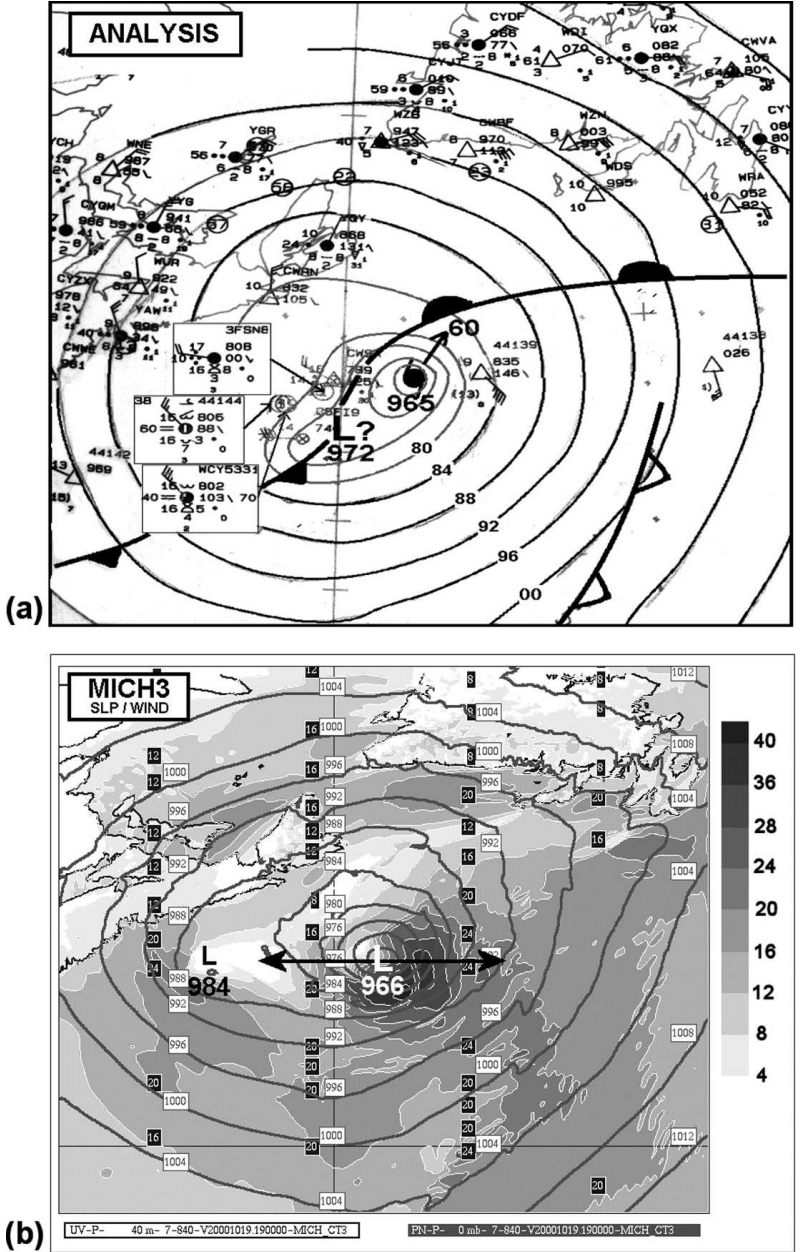

(b)

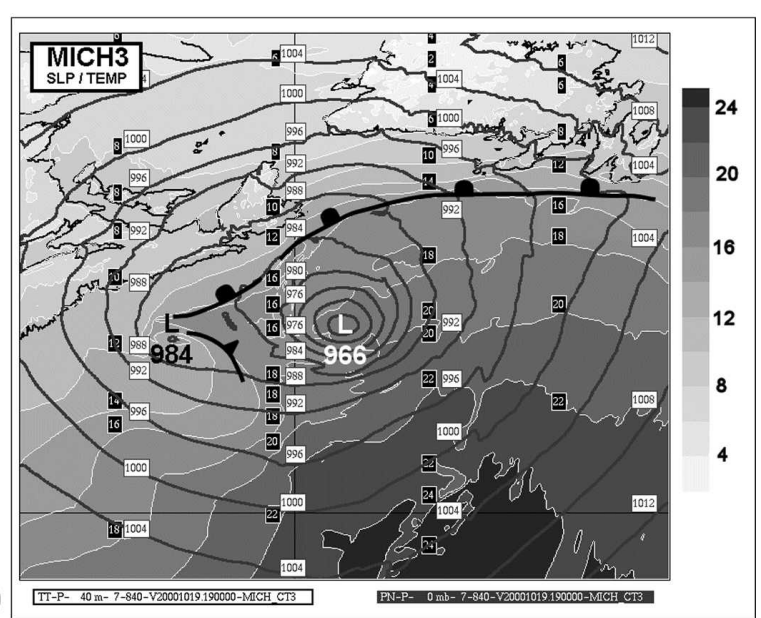

FIG. 11. (a) Manually drawn (subjective) SLP (every $4 \mathrm{hPa}$ ) valid at 1800 UTC 19 Oct; (b) 3-km model control simulation (MICH3) valid at 1900 UTC 19 Oct showing SLP (solid gray contours) and surface $(40 \mathrm{~m})$ wind speed (shaded) every $4 \mathrm{~m} \mathrm{~s}^{-1}$; and (c) same as in (b) but with model-simulated surface $(40 \mathrm{~m})$ temperatures (shaded every $2^{\circ} \mathrm{C}$ ). The estimated position of the baroclinic cyclone in (a) is shown by "L?" and is also marked in (b) and (c). Cross section shown in Fig. 13d was taken along the line shown in (b).

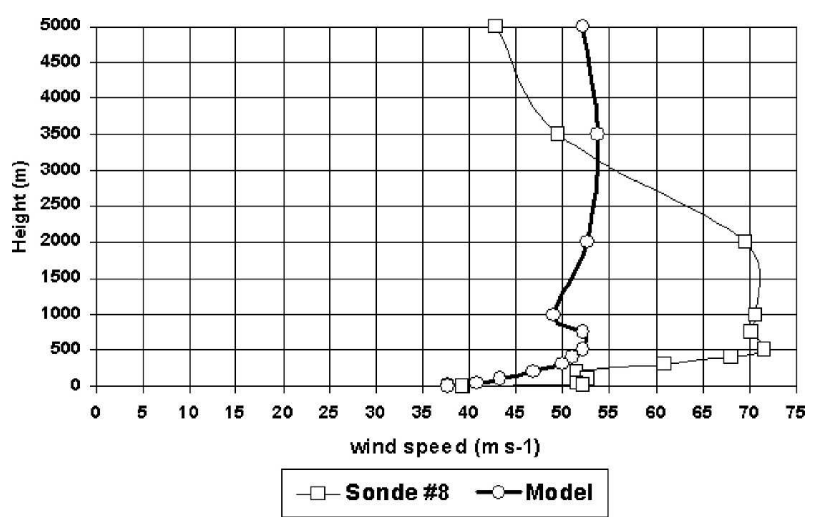

FIG. 12. Vertical profiles of horizontal wind speed from aircraft dropsonde 8 at 1700 UTC 19 Oct and the $3-\mathrm{km}$ run of the model (MICH3) at 1800 UTC 19 Oct. The storm-relative position of the profiles is $85 \mathrm{~km}$ southeast of the surface position of the hurricane.

spectively. All other members in the ensemble are run on the small $12-\mathrm{km}$ grid piloted by analyses from the CMC Data Assimilation System archive (Chouinard et al. 1994). Vortex parameters are perturbed from the control values by amounts similar to the observational errors. Alternate convective parameterizations include Fritsch and Chappel (1980) and Kuo (1974) (fcp and kuo in Table 1). The cloud microphysical member in the ensemble employs the scheme of Kong and Yau (1997).

A composite of the simulated storm tracks from the 17 -member ensemble plus the control run is shown in Fig. 14. The tracks are clustered fairly closely together with no significant outliers. The degree of spread in the tracks with time is also quite small. This is likely because the atmospheric steering flow is very strong and there is not a lot of time for the storm to deviate from the control solution. The mean 24-h error in storm position (valid time 0000 UTC 20 October near landfall) for the ensemble was $161 \mathrm{~km}$. The 24-h CHC operational forecast position for Michael (valid at 0000 UTC 20 October) was $47^{\circ} \mathrm{N}, 60^{\circ} \mathrm{W}$ with maximum surface winds near $28 \mathrm{~m} \mathrm{~s}^{-1}(55 \mathrm{kt})$ and a central pressure of $994 \mathrm{hPa}$. This corresponds to an error in the track forecast of $400 \mathrm{~km}$ and an intensity error of $11 \mathrm{~m} \mathrm{~s}^{-1}(20 \mathrm{kt})$ and $28 \mathrm{hPa}$ too high (compared to the best track) in terms of central pressure, highlighting the difficulty in forecasting this event. Incidentally, subsequent forecasts did improve once it became clear what was happening.

The ensemble means for MSLP and MSW are shown in Fig. 15 compared with the best track. The ensemble means do not differ significantly from the control run (Figs. 7a and 7b), but here we can see the degree of variability among the ensemble members as indicated 


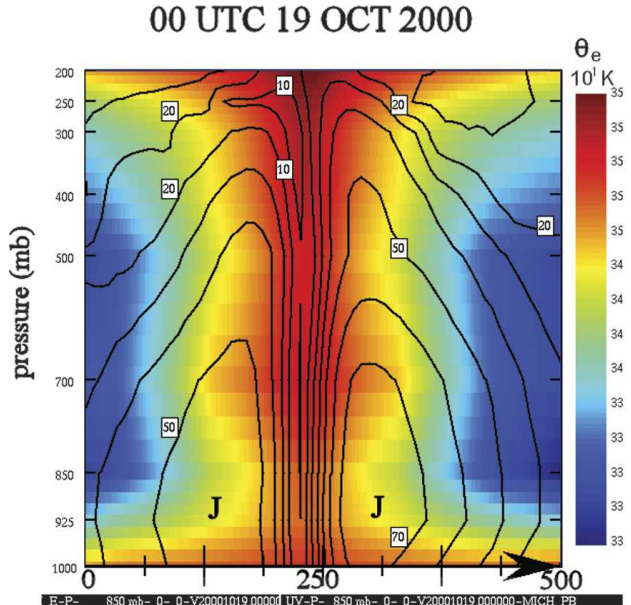

a)

west-east distance $(\mathrm{km})$

12 UTC 19 OCT 2000

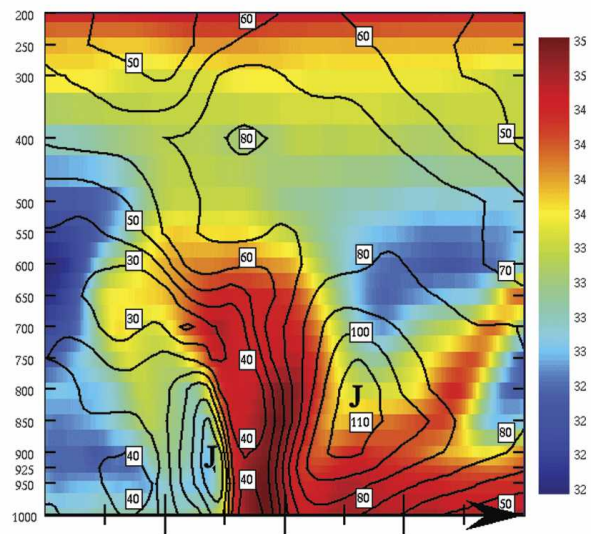

b)

15 UTC 19 OCT 2000

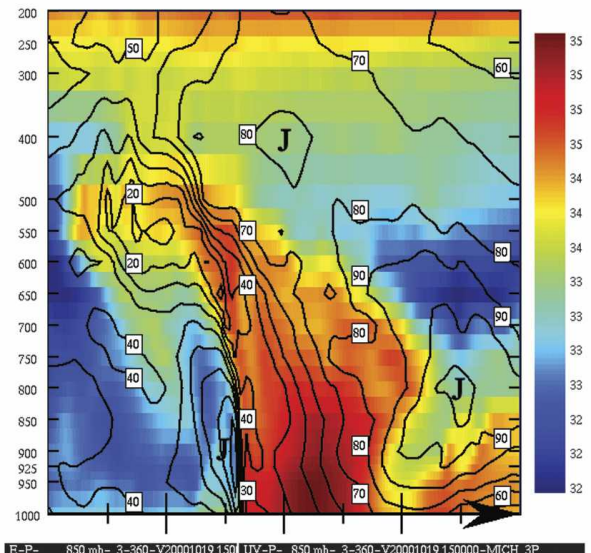

C)
19 UTC 19 OCT 2000

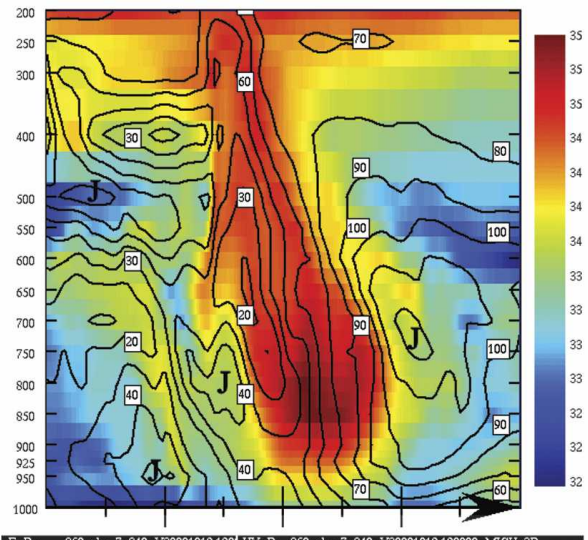

d)

22 UTC 19 OCT 2000

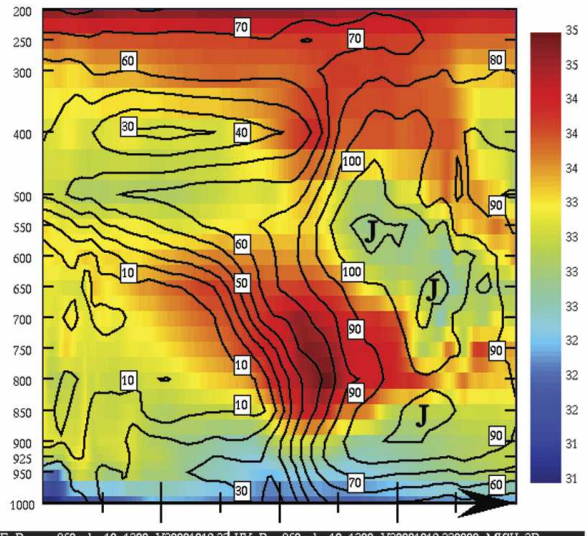

E-P-

00 UTC 20 OCT 2000

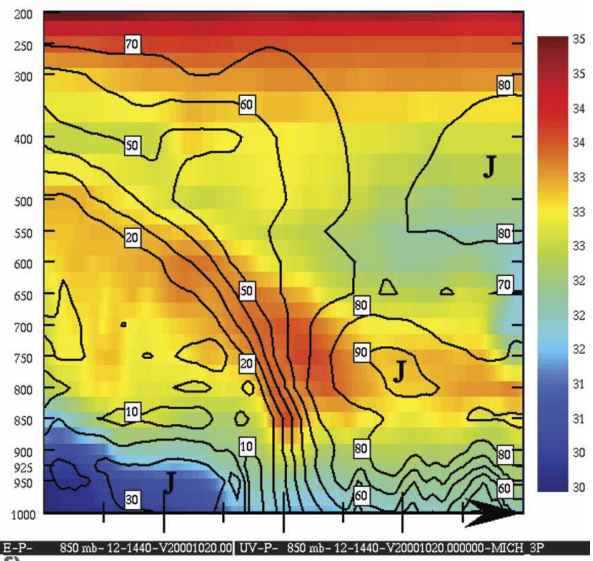

E)

FIG. 13. Vertical cross sections of $\theta_{e}$ (colored field) and horizontal wind speed magnitude (solid contours every $10 \mathrm{kt} ; 1 \mathrm{kt}=\sim 0.515 \mathrm{~m} \mathrm{~s}^{-1}$ ) from the $3-\mathrm{km}$ control simulation (MICH3) at selected times during ET. The cross sections are taken along a west to east line through the storm center [indicated in Fig. 11b for (d)]. (a) The structure of the synthetic vortex at 0000 UTC 19 Oct. 


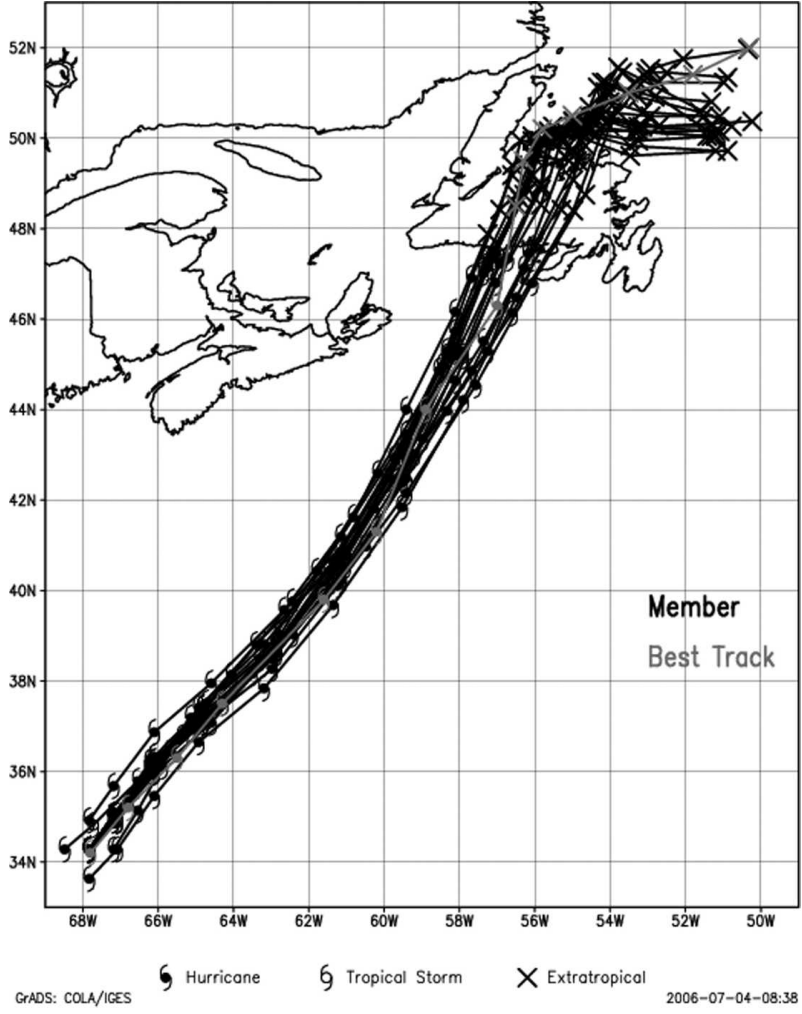

FIG. 14. Storm tracks for all ensemble members (including control) from the set of simulations in Table 1 (black), plus the BT (gray). Track positions are every $3 \mathrm{~h}$ for the 42 -h period from 0000 UTC 19 Oct to 1800 UTC 20 Oct.

by the 1 standard deviation range bars in the plots in Fig. 15. There is a significant amount of variability in MSLP that grows with time during the first $15 \mathrm{~h}$ of the experiments. In terms of MSW, the degree of variability is greatest between simulation hours 9 and 18 . Incidentally, this corresponds very closely to the period when Michael was undergoing ET. The variability then drops after $18 \mathrm{~h}$ and is relatively small after $24 \mathrm{~h}$, which corresponds to the extratropical phase of the storm. The landfall intensity in terms of wind speed at simulation hour 24 does not appear to be highly sensitive to the perturbed initial conditions and model parameters. Much of the variability during the ET period occurs among members employing different convective and cloud microphysical schemes. Note that the variability among the members of the ensemble is not enough to explain the rapid intensification period observed between 15 and $18 \mathrm{~h}$ (in terms of MSLP). This is not a surprise since it is well known that numerical models have difficulty forecasting sudden changes in the intensity of tropical cyclones, given that the processes governing these changes occur at scales unresolved by the model (Krishnamurti et al. 2005).

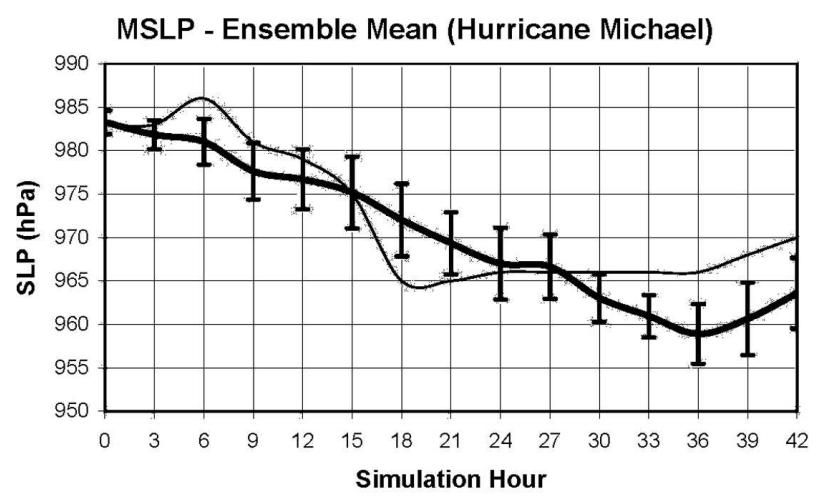

(a)

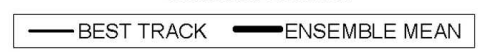

MSW - Ensemble Mean (Hurricane Michael)

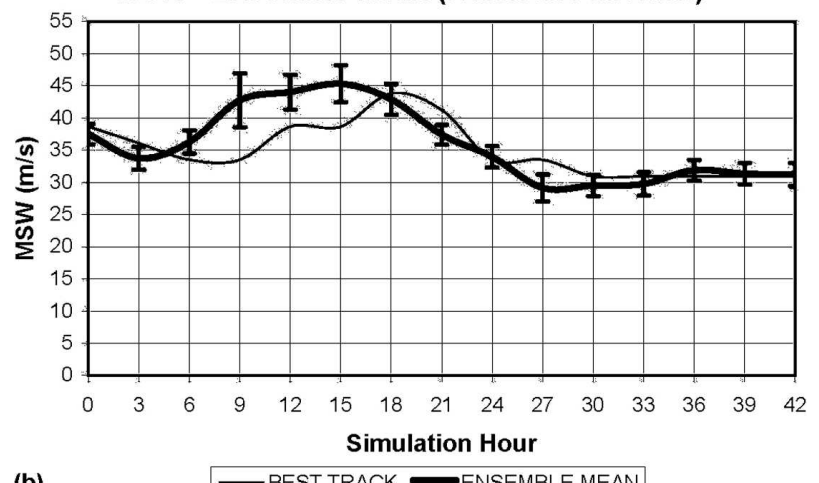

(b)

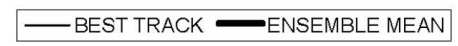

FIG. 15. (a) MSLP and (b) MSW traces for the ensemble mean (thick curve) and the BT (thin curve). Vertical range bars denote the one standard deviation values from the ensemble.

\section{b. Sensitivity to driving fields and domain size}

The experiments examined so far in this paper were driven by large-scale analyses fields that represent the "best" boundary conditions available. However, in order to obtain a better idea of the model's performance for this case in a forecast mode of operation, driving fields from a regional forecast model are used (in this case, from the GEM model). We also test a larger 12$\mathrm{km}$ domain (shown in Fig. 6).

Resulting postlandfall (27HR) sea level pressure and 1000-hPa wind speed analyses from these experiments are summarized in Fig. 16. The control run (MICH12) result is shown in Fig. 16a. Results from the MICH_GSM and MICH_GLG (GEM piloted) runs are shown in Figs. 16b and 16c, respectively. Finally, the resulting sea level pressure and wind analysis from the GEM-piloted NOVOR experiment is shown in Fig. 16d. The general result from these experiments is that the vortex-initiated runs lead to a single, deep area of low pressure over central or eastern Newfoundland, with an area of strong winds over the eastern part of the island. However, there are differences in the storm 

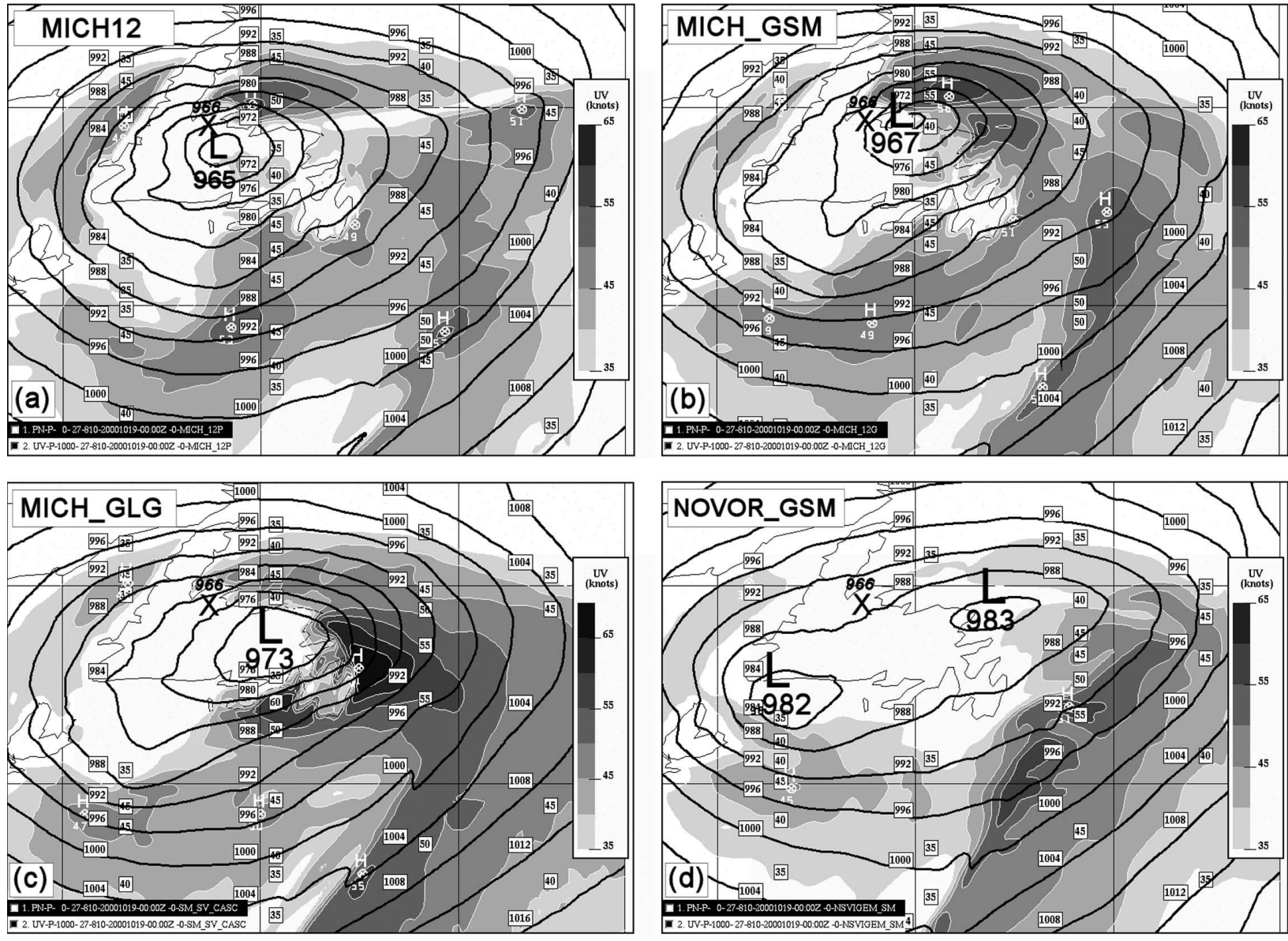

FIG. 16. SLP (black contours) and 1000-hPa wind field (shaded) at simulation hour 27 from the domain and driving-field experiments: (a) small $12-\mathrm{km}$ grid experiment piloted by analyses (MICH12), (b) small 12-km grid experiment piloted by GEM forecasts (MICH_GSM), (c) large 12-km grid experiment piloted by GEM forecasts (MICH_GLG), and (d) small 12-km grid experiment without vortex insertion piloted by GEM forecasts (NOVOR_GSM). SLP interval is $4 \mathrm{hPa}$ and 1000 -hPa wind speed is every $5 \mathrm{kt}$.

structure, position, and intensity that are dependant on the driving fields and domain size. As one might expect, the GEM-piloted runs are not as accurate as the analyses-driven run, and interestingly, the simulation on the larger $12-\mathrm{km}$ grid is slightly worse than on the smaller grid.

It is reasonable to expect the solutions from the GEM-piloted runs to be of lesser quality than those driven by analyses. It is perhaps less obvious that the storm location from the larger $12-\mathrm{km}$ simulation is less accurate than that from the smaller one. To investigate this further, we ran the large and small $12-\mathrm{km}$ grids without vortex insertion for comparison. Slight differences in the evolution of the $500-\mathrm{hPa}$ geopotential height pattern were noted (not shown) as well as notable differences in the sea level pressure field throughout the domain. When comparing the differences in these fields for the MICH_GSM and MICH_GLG runs, similar differences were observed in the far field (as well as near the storm centers) as were seen in the no-vortex comparison. It appears that the different solution for the large domain is not attributable to the vortex insertion, but is most likely owing to the position of propagating features at the edge of the domains at the beginning of the simulations (Landman et al. 2005). In a test case where we pilot the small $12-\mathrm{km}$ grid with output from the large (not shown), we notice no difference in the output of fields in the overlapping region. This indicates compliance with the "acid test," also as demonstrated in section 7c of Thomas et al. (1998). The bottom line from this comparison is that a larger grid does not necessarily equate to an improved hindcastforecast.

\section{c. Comparison with operational guidance}

A summary of the operational numerical model track and intensity forecasts issued at 0000 UTC 19 October is shown in Figs. 17 and 18. Shown in this operational 


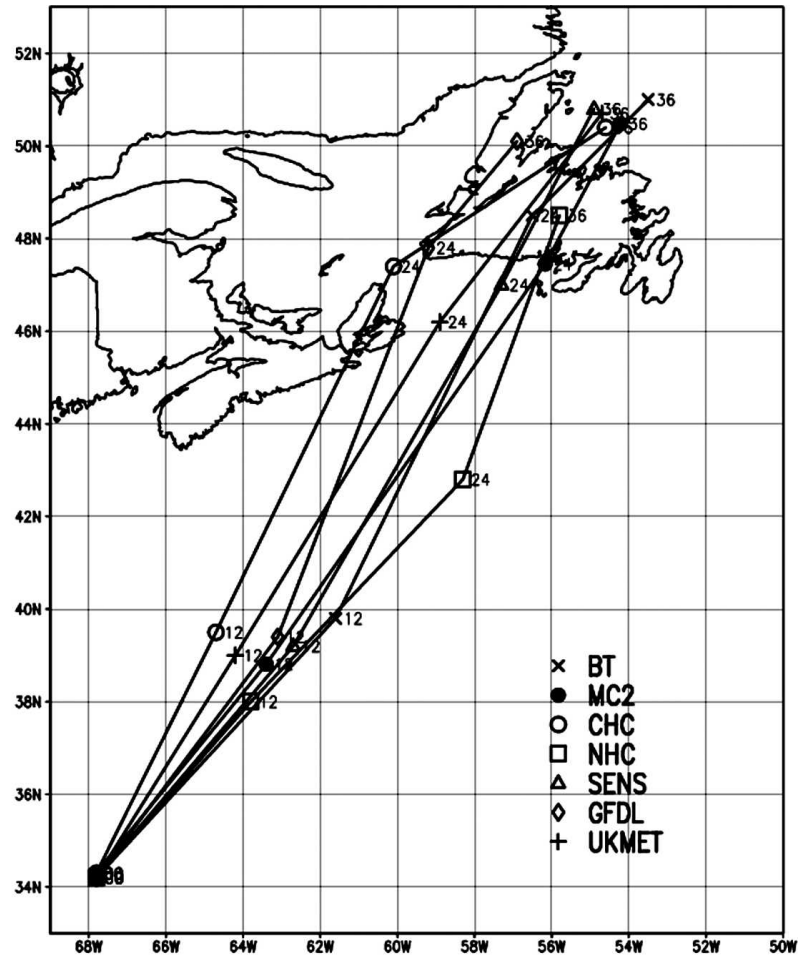

GADS: COLNIGES

2006-07-03-17:52

FIG. 17. Operational and numerical track forecasts for Hurricane Michael for a 36-h period beginning 0000 UTC 19 Oct.

suite of guidance is the Florida State Superensemble (SENS), which contains information from various dynamical models to produce a weighted ensemble mean (weighting being proportional to the past performance of model members) as described by Williford et al. (2003). Also shown are the UKMET and GFDL models, which were introduced in section 1 . The CHC and NHC forecasts are based on a forecaster's "blend" of

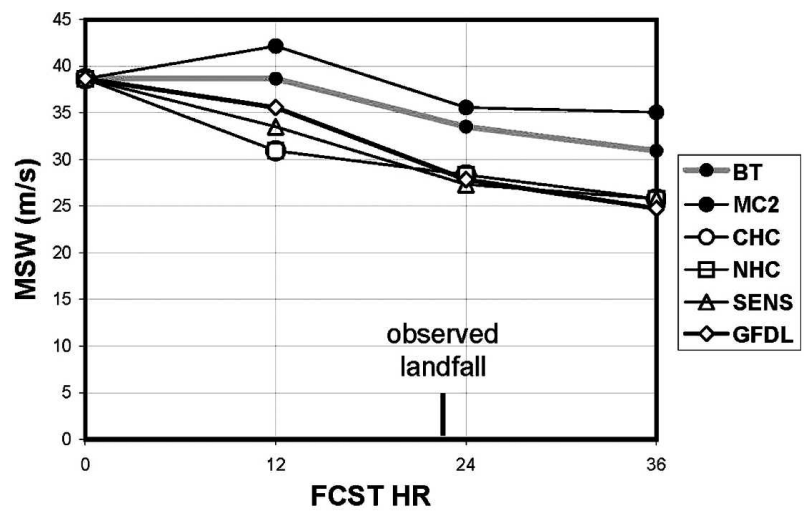

FIG. 18. Operational and numerical intensity forecasts in terms of maximum sustained (surface) winds (MSW) for Hurricane Michael for a 36-h period beginning 0000 UTC 19 Oct. all available guidance including the dynamical models shown in the figures. Finally, the results from the MICH_GSM experiment (labeled MC2) are shown because it mimics the forecast mode of operation. The point here is that the MC2 falls within the range of other dynamical models and guidance, suggesting that even simple vortex insertion prior to the ET of Michael in forecast mode would provide useful guidance to forecasters.

\section{d. Sensitivity to SST}

As a final sensitivity experiment, we conduct simulations identical to MICH12 and MICH3 using the climatological SST from Geshelin et al. (1999). The climatology is organized into monthly means, which are used to find the equivalent climatology for 19 October using a weighted average of October and November data. The data have a resolution of $18.5 \mathrm{~km}$ and are interpolated to the 28-km "piloting" domain for the model (see Fig. 6). A map showing the observed minus climatology SST (anomaly) with the storm track is shown in Fig. 19. The SSTs were near normal south of $\sim 40^{\circ} \mathrm{N}$ and anomalously warm north of that along the storm track, with the largest anomaly of $3^{\circ}-4^{\circ} \mathrm{C}$ near $43^{\circ} \mathrm{N}$.

Results from the climatology SST runs (CLIM12 and CLIM3) are shown in Figs. 8 and 9. The impact on the storm track is negligible, especially when compared with the variability in the tracks from the ensemble system. There appears to be some impact on storm intensity, but the signal is not as significant as that observed during similar experiments with Hurricane Juan while it was approaching Nova Scotia in September 2003 (Fogarty et al. 2006). For instance, there is not a great difference in MSLP and MSW between the MICH3 and CLIM3 at the time of landfall (see Figs. 9a and 9b). The only difference in MSW that appears to be significant occurs during the high-resolution runs (MICH3 and CLIM3) between 14 and $18 \mathrm{~h}$. This corresponds to the period when the simulated storm traveled between $40^{\circ}$ and $43^{\circ} \mathrm{N}$ over the warm SST anomalies shown in Fig. 19.

As noted above, the landfalling intensity is not overly sensitive to the (relatively) small departures of SSTs from climatology. This is not surprising since the synoptic environment is most conducive to baroclinic intensification of the storm, as opposed to tropical-type intensification (through oceanic heat transfer).

\section{Summary and conclusions}

A mesoscale model of the atmosphere was used to simulate the extratropical transition (ET) of Hurricane 


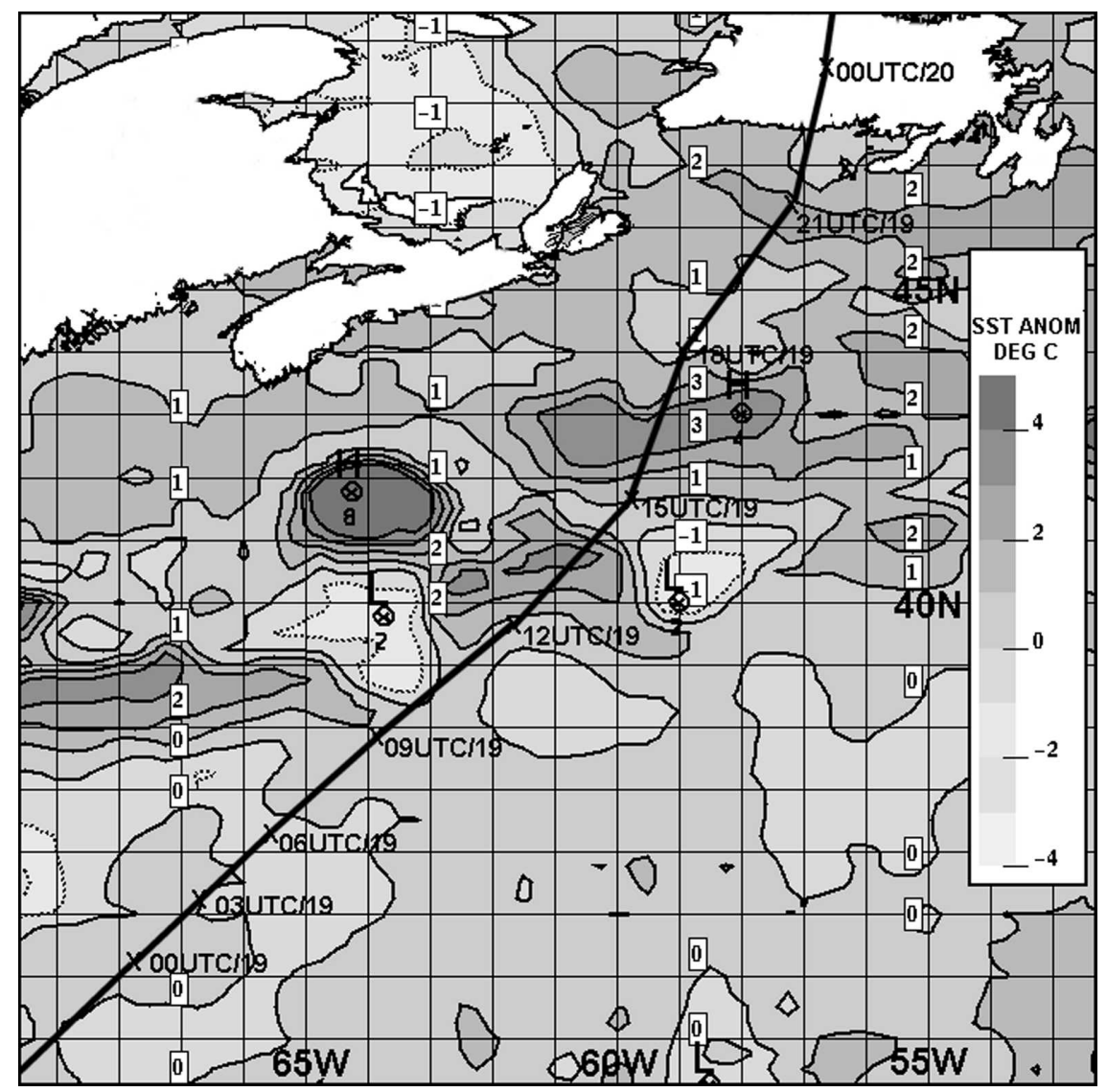

FIG. 19. SST anomaly valid at 0000 UTC 19 Oct (every $1^{\circ} \mathrm{C}$ ). The negative anomaly is represented by dotted contours. Partial storm track for Hurricane Michael also shown.

Michael during its approach to Newfoundland in October 2000. A synthetic three-dimensional hurricane vortex was constructed prior to running the model and used to replace the poorly represented cyclone in the large-scale analysis fields. The improved initial conditions (by introducing more heat, moisture, and kinetic energy into the storm region) allowed for much more realistic simulations of the storm than was the case without inserting a synthetic vortex. This fundamental improvement in the initial fields also leads to improved numerical hindcasts in other cases, as shown for Hurricane Juan in 2003 by Fogarty et al. (2006) and Tropical Storm Karen in 2001 (Fogarty 2006), which also underwent ET, but without the reintensification observed during Michael.

The model was used to diagnose the structural changes of Hurricane Michael during ET and to study the sensitivity of hindcast simulations to various initial conditions, lateral driving fields, domain sizes, and model parameters.

During Michael's early stage of ET, the model successfully simulated the absorption of a baroclinic cy- clone into the hurricane circulation. On the other hand, when a hurricane vortex was not used in the initial conditions, the baroclinic cyclone became the dominant circulation. During the actual event, forecasters were not sure which scenario would materialize until approximately $6 \mathrm{~h}$ before landfall. We suggest that the model would be a valuable forecast tool during situations such as this, particularly when the tropical cyclone is poorly represented in the model initial conditions. Simulations from the present study were driven by synoptic-scale analyses, which is obviously not possible when employing the model as a predictive tool. Nonetheless, a "pseudoforecast" (piloted by synoptic-scale numerical weather forecasts) conducted as a test for Hurricane Michael led to an improved representation of the storm life cycle as in the simulations piloted by the analyses. The pseudoforecast also compared well to operational guidance available during the event.

The model simulated the intensification of Michael within a baroclinic environment while traversing sea surface temperatures less than $26^{\circ} \mathrm{C}$. When run at $3-\mathrm{km}$ resolution and driven by large-scale analyses, the model 
produced a realistic storm intensity at landfall with central pressure of $967 \mathrm{hPa}$ (compared to an observed pressure of $966 \mathrm{hPa}$ ) and maximum surface winds of $\sim 36$ $\mathrm{m} \mathrm{s}^{-1}$ (compared to observed winds of $\sim 39 \mathrm{~m} \mathrm{~s}^{-1}$ ).

Aircraft measurements of Hurricane Michael showed the presence of a deep layer of strong winds on the southeastern side of the storm. The model also simulated this structure, but the modeled winds were not as intense as the observed winds. Aircraft, satellite, and radar data indicated that Michael was tilted toward the east or northeast prior to landfall, at least below the 500-hPa level. The model showed storm tilt toward the northwest originally then toward the east and northeast during its approach to southern Newfoundland, which was consistent with the observed tilt during that time.

The variability in the storm intensity (in terms of maximum wind speeds) among the sensitivity experiments was greatest during the ET phase of the storm, while it was much less during the extratropical phase. The simulations were sensitive to the choice of lateral piloting fields (analyses versus forecasts) and to the choice of domain size. The model was not able to simulate the most rapid period of intensification (in terms of central sea level pressure) but this is a common problem with numerical models and, in this case, did not have a significant influence on the landfalling intensity of the storm in Newfoundland.

When testing the role of warm SST anomalies along the track of Michael by running a climatological SST simulation, the intensity appeared to be sensitive to the local SST anomaly between $40^{\circ}$ and $43^{\circ} \mathrm{N}(\sim 2.5-5$ $\mathrm{m} \mathrm{s}^{-1}$ weaker winds than in the control run) yet there was no significant impact on storm intensity at or following landfall. Because Michael was in a rapidly changing baroclinic state and moving very quickly, there was little opportunity for ocean heat transfer to have a strong influence, unlike a more tropical-type intensification, as in Hurricane Juan (Fogarty et al. 2006).

The degree of spread among the ensemble members was comparable to the spread among various operational dynamical models, making the MC2 (with simple vortex insertion prior to ET) a potential operational forecasting tool for short-range prediction of hurricanes undergoing ET in eastern Canada.

Acknowledgments. We thank those who have helped in setting up the modeling system and provided technical support throughout the course of this project. They include Serge Desjardins, Ron McTaggart-Cowan, Mike Casey, Weiqing Zhang, Stephane Chamberland, Yves Chartier, Michel Desgagne, Pierre Pellerin, Bruce Brasnett, and Rick Danielson. We also thank James
Franklin for quality controlling some of the aircraft dropsonde data. This project has received funding from the Meteorological Service of Canada (MSC), the NSERC/MARTEC/MSC Industrial Research Chair, and a project grant from the Canadian Foundation for Climate and Atmospheric Sciences. We are also grateful to the MSC for providing access to the supercomputer facility in Dorval, Quebec, Canada, where the model runs were carried out, and to the National Research Council in partnership with MSC for collection of the aircraft data used in this study.

\section{REFERENCES}

Abraham, J., W. Strapp, C. Fogarty, and M. Wolde, 2004: Extratropical transition of Hurricane Michael: An aircraft investigation. Bull. Amer. Meteor. Soc., 85, 1323-1339.

Agusti-Panareda, A., C. D. Thorncroft, G. C. Craig, and S. L. Gray, 2004: The extratropical transition of Hurricane Irene (1999): A potential-vorticity perspective. Quart. J. Roy. Meteor. Soc., 130, 1047-1074.

Benoit, R., J. Côté, and J. Mailhot, 1989: Inclusion of a TKE boundary layer parameterization in the Canadian regional finite-element model. Mon. Wea. Rev., 117, 1726-1750.

- M. Desgagné, P. Pellerin, S. Pellerin, S. Desjardins, and Y. Chartier, 1997: The Canadian MC2: A semi-Lagrangian, semi-implicit wideband atmospheric model suited for finescale process studies and simulation. Mon. Wea. Rev., 125, 2382-2415.

Chouinard, C., J. Mailhot, H. L. Mitchell, A. Staniforth, and R. Hogue, 1994: The Canadian Regional Data Assimilation System: Operational and research applications. Mon. Wea. Rev., 122, 1306-1325.

Colle, B. A., 2003: Numerical simulations of the extratropical transition of Floyd (1999): Structural evolution and responsible mechanisms for the heavy rainfall over the northeast United States. Mon. Wea. Rev., 131, 2905-2926.

Davidson, N. E., and H. C. Weber, 2000: The BMRC highresolution tropical cyclone prediction system: TC-LAPS. Mon. Wea. Rev., 128, 1245-1265.

_ mentation of the JMA typhoon bogus in the BMRC tropical prediction system. J. Meteor. Soc. Japan, 71, 437-467.

Davis, C. A., and L. F. Bosart, 2003: Baroclinically induced tropical cyclogenesis. Mon. Wea. Rev., 131, 2730-2747.

Evans, J. L., and R. E. Hart, 2003: Objective indicators of the life cycle of extratropical transition for Atlantic tropical cyclones. Mon. Wea. Rev., 131, 909-925.

_ J. M. Arnott, and F. Chiaromonte, 2006: Evaluation of operational model cyclone structure forecasts during extratropical transition. Mon. Wea. Rev., 134, 3054-3072.

Fogarty, C. T., 2006: Numerical modeling of Atlantic hurricanes moving into the middle latitudes. Ph.D. thesis, Dalhousie University, Halifax, NS, Canada, 176 pp.

_ , R. J. Greatbatch, and H. Ritchie, 2006: The role of anomalously warm sea surface temperatures on the intensity of Hurricane Juan (2003) during its approach to Nova Scotia. Mon. Wea. Rev., 134, 1484-1504.

Frank, W. M., and E. A. Ritchie, 1999: Effects of environmental flow upon tropical cyclone structure. Mon. Wea. Rev., 127, 2044-2061. 
Fritsch, J. M., and C. F. Chappel, 1980: Numerical prediction of convectively driven mesoscale pressure systems. Part I: Convective parameterization. J. Atmos. Sci., 37, 1722-1733.

Fujita, T., 1952: Pressure distribution within a typhoon. Geophys. Mag., 23, 437-451.

Gal-Chen, T., and R. Somerville, 1975: On the use of a coordinate transformation for the solution of the Navier-Stokes equations. J. Comput. Phys., 17, 209-228.

Geshelin, Y., J. Sheng, and R. J. Greatbatch, 1999: Monthly mean climatologies of temperature and salinity in the western North Atlantic. Canadian Tech. Rep. on Hydrography and Ocean Sciences 153, vi+62 pp.

Hart, R. E., 2003: A cyclone phase space derived from thermal wind and thermal asymmetry. Mon. Wea. Rev., 131, 585-616.

— , and J. L. Evans, 2004: Synoptic composites of the extratropical transition lifecycle of North Atlantic TCs as defined within cyclone phase space. Preprints, 26th Conf. on Hurricanes and Tropical Meteorology, Miami Beach, FL, Amer. Meteor. Soc., 681-682.

- - - and C. Evans, 2006: Synoptic composites of the extratropical transition life cycle of North Atlantic tropical cyclones: Factors determining posttransition evolution. Mon. Wea. Rev., 134, 553-578.

Heming, J. T., and A. M. Radford, 1998: The performance of the United Kingdom Meteorological Office Global Model in predicting the tracks of Atlantic tropical cyclones in 1995. Mon. Wea. Rev., 126, 1323-1331.

Jones, S. C., and Coauthors, 2003: The extratropical transition of tropical cyclones: Forecast challenges, current understanding, and future directions. Wea. Forecasting, 18, 1052-1092.

Kain, J. S., and J. M. Fritsch, 1990: A one-dimensional entraining/ detraining plume model and its application in convective parameterization. J. Atmos. Sci., 47, 2784-2802.

Kimball, S. K., and J. L. Evans, 2002: Idealized numerical simulations of hurricane-trough interaction. Mon. Wea. Rev., 130, 2210-2227.

Klein, P. M., P. A. Harr, and R. L. Elsberry, 2002: Extratropical transition of western North Pacific tropical cyclones: Midlatitude and tropical cyclone contributions to reintensification. Mon. Wea. Rev., 130, 2240-2259.
Kong, F., and M. K. Yau, 1997: An explicit approach of microphysics in MC2. Atmos.-Ocean, 35, 257-291.

Krishnamurti, T. N., S. Pattnaik, L. Stefanova, T. S. V. Kumar, B. P. Mackey, A. J. O'Shay, and R. J. Pasch, 2005: The hurricane intensity issue. Mon. Wea. Rev., 133, 1886-1912.

Kuo, H. L., 1974: Further studies on the parameterization of the influence of cumulus convection on large-scale flow. J. Atmos. Sci., 31, 1232-1240.

Kurihara, Y., M. A. Bender, R. E. Tuleya, and R. J. Ross, 1995: Improvements in the GFDL hurricane prediction system. Mon. Wea. Rev., 123, 2791-2801.

Landman, W. A., A. Seth, and S. J. Camargo, 2005: The effect of regional climate model domain choice on the simulation of tropical cyclone-like vortices in the southwestern Indian Ocean. J. Climate, 18, 1263-1274.

McTaggart-Cowan, R., J. R. Gyakum, and M. K. Yau, 2001: Sensitivity testing of extratropical transitions using potential vorticity inversions to modify initial conditions: Hurricane Earl case study. Mon. Wea. Rev., 129, 1617-1636.

_, E. Atallah, J. R. Gyakum, and L. F. Bosart, 2006: Hurricane Juan (2003). Part II: Forecasting and numerical simulation. Mon. Wea. Rev., 134, 1748-1771.

Monin, A. S., and A. M. Obukhov, 1954: Basic laws of turbulent mixing in the surface layer of the atmosphere. Tr. Geofiz. Inst., Akad. Nauk SSSR, 151, 163-187.

Ritchie, E. A., and R. L. Elsberry, 2001: Simulations of the transformation stage of the extratropical transition of tropical cyclones. Mon. Wea. Rev., 129, 1462-1480.

Stewart, S. R., 2000: Tropical cyclone report for Hurricane Michael: 17-19 October 2000. NCEP Rep., 13 pp. [Available online at http://www.nhc.noaa.gov/2000michael.html.]

Thomas, S. J., C. Girard, R. Benoit, M. Desgagné, and P. Pellerin, 1998: A new adiabatic kernel for the MC2 model. Atmos.Ocean, 36, 241-270.

Tremblay, A. A., W. Yu, and R. Benoit, 1996: An explicit cloud scheme based on a single prognostic equation. Tellus, 48A, 483-500.

Williford, C. E., T. N. Krishnamurti, R. C. Torres, S. Cocke, Z. Christidis, and T.S. Vijaya Kumar, 2003: Real-time multimodel superensemble forecasts of Atlantic tropical systems of 1999. Mon. Wea. Rev., 131, 1878-1894. 